\title{
The Evolution of Physician Density in Switzerland
}

\author{
Gabrielle Wanzenried ${ }^{a}$ and Sandra Nocera ${ }^{b c}$
}

JEL-Classification: I11, I18, C33

Keywords: physician density, demand for health services, health policy, panel data

\section{Introduction}

How do medical doctors choose where to practice? Why are there many physicians in certain areas of a country and few in others? How has the distribution of physicians changed over time, and what are the driving forces behind the changes? Are there differences between general practitioners and specialists? Is there need and room for policy intervention to affect the distribution of physicians across different regions of a country? Even though these and related questions have challenged economists for some time, the answers are anything but clear. This paper is an attempt to shed more light on these complex issues for the particular case of Switzerland.

Considerations related to the distribution of physicians are relevant for several reasons: For most countries health is a special good in the sense that everybody should have access to health care. Therefore, that access is typically seen as a constitutional right. From this point of view, a shortage of physicians as well as an unequal geographical distribution of both general practitioners and specialists should be avoided. On the other hand, it is often argued that the health costs per capita increase with the number of physicians (see Schmid, 1984). Not only are

a Lucerne University of Applied Sciences And Arts, Institute of Financial Services Zug IFZ.

b Foundation Swiss School of Public Healthplus, Zurich.

c Corresponding address: Gabrielle Wanzenried, Lucerne University of Applied Sciences and Arts, Institute of Financial Services Zug IFZ, Grafenauweg 10, CH-6304 Zug, Switzerland; phone: + 41 (0)4172465 64, email: gabrielle.wanzenried@hslu.ch. We would like to thank Mike Gerfin, Bronwyn H. Hall, Robert E. Leu, Markus König, Heather Murray, Heidi Seney, Roland Unternährer, participants of the EARIE Conference 2002, Madrid, the World Congress of the International Health Economics Association 2003, San Francisco, and the annual conference of the Verein für Socialpolitik 2005 in Bonn and an anonymous referee for helpful suggestions and comments and the Swiss Federal Statistical Office for data provision. Gabrielle Wanzenried acknowledges financial support of the Swiss National Science Foundation. All errors are our sole responsibility. 
they important suppliers of health services, but it is widely held that physicians may also be able to affect the extent to which their patients consume services by using their superior knowledge (see FolLand et al., 2001). Even though these issues are not addressed in our paper, it is worth mentioning that the possibility of physicians inducing demand to serve their own interests might call for policy intervention.

Physician densities in Switzerland also vary substantially among the different regions. This unequal geographic distribution and the positive correlation between the number of physicians and health care costs are often seen as evidence for demand inducement and, therefore, market failure. Up to 2002, when the Swiss government introduced to freeze new accreditations for physicians in private practice sites in Switzerland, no specific policies have been implemented in Switzerland to reduce these inequalities. It is likely, however, that this measure will be given up in the future because it is considered as ineffective. Such a behavior stands in contrast to, e.g., the U.S. and Canada, where policy interventions ${ }^{1}$ have aimed to eliminate the unequal distributions commonly associated with market failure. As New HOuse et al. (1982) outline, unequal distributions across geographic areas may well be consistent with well-functioning markets.

A number of papers have investigated physicians' location decisions. KRIsTIANSEN and FøRDE (1992) use cross-sectional data from Norway to provide evidence for the hypothesis that the location of internship and residency training affects a doctor's future work location choice. CHOMITZ ET AL. (1998) show that changes in the incentive system for medical school graduates in Indonesia influences doctors' location decisions. HuRley (1990) investigates the role of income in physicians' practice decisions. His simulation results with longitudinal survey data of U.S. medical school graduates reveal that physicians seem to respond to financial incentives and that income-based policies may, therefore, be effective in redistribution. Bolduc et al. (1996) assess the effects of various incentive measures introduced in Quebec to influence the geographical distribution of physicians. They find that region-specific incentive measures have reduced geographical inequalities in the distribution of general practitioners. Finally, FosTer and Gorr (1992) use annual state-level data from the U.S. for the period 1965-1982 to assess the impact of federal policies from the 1960s and 1970s that aimed to

1 Possible policy measures include restricting the number of postgraduate training and practice sites in the most popular areas, compensating medical school graduates with shorter compulsory service, improving career opportunities or financial incentives for working in remote places. Because physicians prefer to work where they are trained, another policy is to locate medical schools and postgraduate training sites in the less popular regions (see Hurley, 1990). 
increase physician supply and reduce spatial inequalities. Their results suggest that federal policy was effective for primary care physicians, but much less for specialists.

The aim of this paper is to analyze the evolution of physician densities across the 26 Swiss cantons from 1960 to 2005. Similar to Foster and Gorr (1992), we use a physician location model that relates the percentage growth in physician population of a canton to a set of aspects. In particular, we take into account three sets of factors. The first set of determinants refers to the relative number of physicians that are already practicing in a canton and to the division of work between the general practitioners and the specialists. We refer to these factors as saturation and substitution effects. The second set of factors provides a rough approximation of the demand for physician services related to the demographic and socio-economic characteristics of the population, i.e. the growth of the population, the per capita income and the average age. The third set of variables included in our analysis captures the medical infrastructure in a certain area, namely the number of hospital beds and the existence of a university hospital. Furthermore, we examine whether general practitioners and specialists differ in their behavior.

The paper brings several new aspects to the problem. It is the first paper to analyze the evolution of physician densities in Switzerland over a long period of time. In contrast to FosTer and GorR (1992), we provide a more elaborate characterization of both demand and supply side not only by considering population growth and physician density, but also by taking into account the population's income and age and their changes over time. Moreover, we explicitly control for physicians' compensation practices, which prove to be quite heterogeneous across regions. We also include variables that capture the medical infrastructure of a canton, which is considered as another important determinant of physician supply. Finally, we allow for non-linear relationships between physician growth and physician density, which seems to be a reasonable characterization of the underlying mechanisms.

From our panel data analysis over the time period from 1960 to 2005, we find evidence that general practitioners and specialists react at least partly in different ways to the main determinants of physician density and their changes over time. In particular, an already high level of specialists in a canton seems to discourage other specialists to open a new practice site. General practitioners mainly seem to avoid areas where the density of specialists has reached a certain level. This is evidence for substitution effects between the services of both physician types, i.e., specialists provide services that could be offered also by general practitioners. Finally, we also find a different impact of freezing the number of practice sites. 
This policy measure, which was imposed by the government in 2002, seems to have mainly affected general practitioners.

The paper is structured as follows: Section 2 describes the evolution of physician densities and related policy issues in Switzerland. Section 3 outlines the main determinants of physician density in an area. The empirical model and the data are in Section 4. Section 5 presents the analysis with the results, and Section 6 concludes. The appendix provides some supplementary statistics.

\section{Physician Density in Switzerland}

Like most other countries, Switzerland has been experiencing rapidly rising health care costs in the last 50 years. In 2004, each Swiss citizen consumed health care services of US\$ 4,077 on average, the third highest per capita consumption worldwide after Luxembourg and the U.S., and corresponding to $159 \%$ of the OECD average. In an attempt to contain costs in health care, competitive elements were introduced in the Swiss health system reform of 1996. The mandatory basic health insurance package fixed by the Swiss government can be bought from any health insurance company. To draw customers, the health insurance companies are required to offer attractive premiums. In order to be profitable, the health insurance companies then have to force physicians to provide costeffective services. In addition, managed care plans are allowed and consumer incentives were introduced. ${ }^{2}$

In reality, many regulations counterbalance these competitive elements. For example, health insurance companies may neither adjust premiums according to risk nor choose among physicians, but must reimburse any mandatory service. ${ }^{3}$ Furthermore, most physicians are still paid on a fee-for-service basis, in which services are charged at rates negotiated between the association of health insurers (Santésuisse) and the Swiss Medical Association (FMH). Because of this compensation policy, physicians could easily open their own practices since they do not generally bear large financial risks once they have a medical degree. In summer 2002, however, a governmental decision was introduced to freeze

2 For instance, a choice of deductibles is given. For further details, see e.g. Schellhorn (2001) or Domenighetti and Crivelli (2001).

3 Except for managed care plans, e.g. HMOs where care is provided through a specific network of health care providers. According to Comparis, these plans, however, insure only about $11 \%$ of the Swiss population. 
new accreditations for physicians in private practice sites in Switzerland. ${ }^{4}$ This measure was motivated by the commonly made assumption that the number of physicians is a main determinant of high health care costs. After six years, it has largely proven as ineffective, and the Swiss parliament is currently discussing about abolishing this rule and introducing other instruments to contain health care costs. ${ }^{5}$

When talking about physician density, we must also look at the Swiss medical education. Medical school graduates, who study medicine for about seven years at a university, spend approximately another six years ${ }^{6}$ working as assistant doctors in hospitals before being certified as FMH-physicians. This qualification is required in order to obtain one of the few permanent specialist positions in hospitals thereafter. As an alternative to a hospital career, physicians can start private practice, either as GPs or as specialists. ${ }^{7}$ The decision to specialize is usually taken after graduate school and affects the choice of training site. When students begin their medical educations, the development of physicians in 12 to 15 years is determined. Therefore, any policy aiming to influence the number of medical students does not affect the number of physicians until a generation later.

Figure 1 shows the evolution of physician densities over the period from 1960 to 2005 , for both general practitioners and specialists with their practice site and averaged over all 26 cantons of Switzerland. In 1960, the two series started at similar levels. On average, 42 general practitioners serve 100,000 persons or one general practitioner treats 2,479 persons, whereas for the specialists the numbers are 38 physicians per 100,000 persons or 3,649 persons per physician, respectively (Table 1).

Until 1975 the physician density was considered too small, being below the number recommended by the World Health Organization. ${ }^{8}$ While physician density remained rather stable, the Swiss economy flourished and social security systems expanded. Due to easier access to medical schools, the number of medical students tripled between 1960 and 1974, ${ }^{9}$ resulting in an increase in the number of physicians 15 years later. General practitioners and specialists grew by $51 \%$ and

4 See 'The Swiss Federal Council: Verordnung über die Einschränkung der Zulassung von Leistungserbringern zur Tätigkeit zu Lasten der obligatorischen Krankenversicherung', 2002.

5 Neue Zürcher Zeitung (NZZ) 05.03.2008.

6 The exact length of time spent depends on the field of specialization. For further details see the regulations of the Swiss Medical Association FMH under http://www.fmh.ch/fmh.

7 A general practioner needs to have the minimum training time of two years as an assistant doctor to open a private practice.

8 Neue Zürcher Zeitung (NZZ), 15.11.1974.

9 The requirement to study Latin in high school had been eliminated. 
Table 1: Average Physician Densities for Switzerland

\begin{tabular}{lcccc}
\hline & \multicolumn{2}{c}{ General practitioners } & \multicolumn{2}{c}{ Specialists } \\
Year & $\begin{array}{c}\text { Per } 100,000 \\
\text { persons }\end{array}$ & $\begin{array}{c}\text { Persons } \\
\text { per generalist }\end{array}$ & $\begin{array}{c}\text { Per 100,000 } \\
\text { persons }\end{array}$ & $\begin{array}{c}\text { Persons } \\
\text { per specialist }\end{array}$ \\
\hline 1960 & 42 & 2,479 & 38 & 3,649 \\
1970 & 36 & 2,915 & 41 & 3,914 \\
1980 & 43 & 2,429 & 60 & 2,275 \\
1990 & 56 & 1,824 & 80 & 1,549 \\
1998 & 60 & 1,694 & 105 & 1,184 \\
2000 & 67 & 1,488 & 126 & 793 \\
2001 & 67 & 1,494 & 128 & 783 \\
2002 & 67 & 1,499 & 129 & 772 \\
2003 & 63 & 1,578 & 138 & 727 \\
2004 & 63 & 1,576 & 140 & 712 \\
2005 & 46 & 2,158 & 158 & 634 \\
\hline
\end{tabular}

Figure 1: Physician Densities from 1960 to 2005 (per 100.000 Persons)

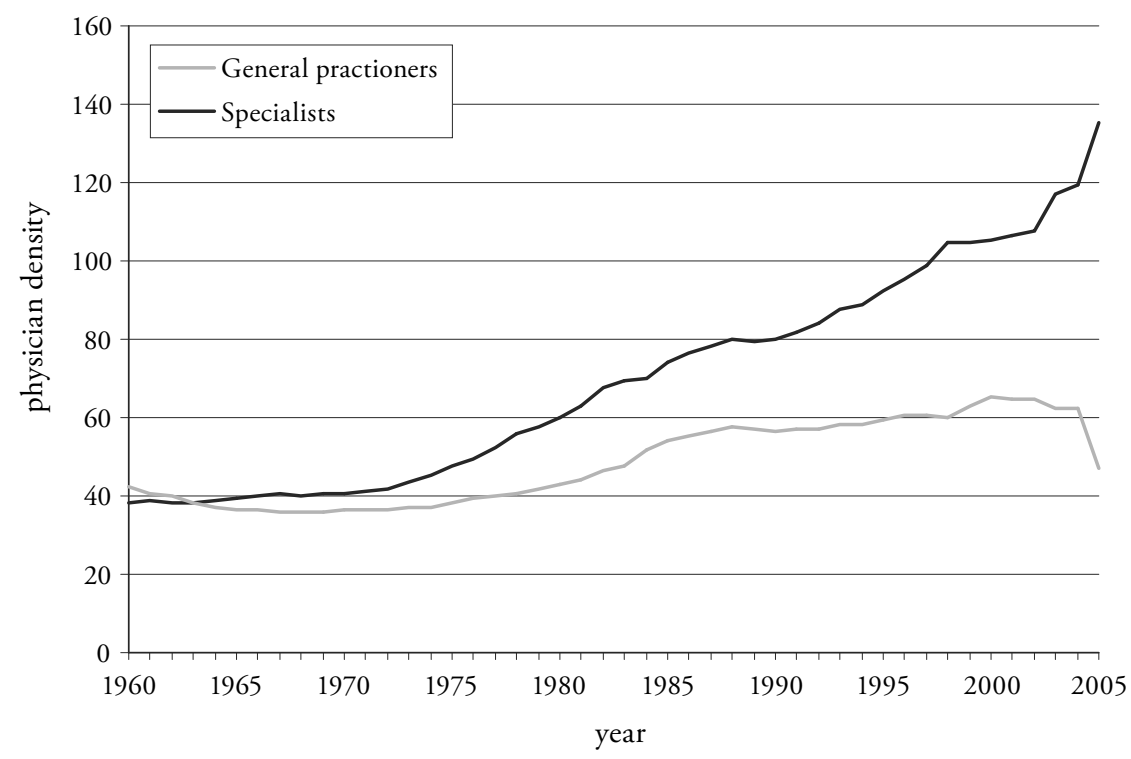


$344 \%$, respectively, but the population had increased by only $38 \%$ from 1960 to 2005 . Because the number of specialists grew faster than that of general practitioners, densities differ substantially in 2005, when 156 specialists but only 46 general practitioners served 100,000 persons on average. Similar developments have been observed in the U.S. and in Canada (see, e.g., Bolduc et al., 1996).

Since 1980, the physician density, particularly of specialists, has been regarded as too high. ${ }^{10}$ Nevertheless, access to medical education was not restricted until 1998. Interventions were limited to information campaigns held in high schools to inform potential medical students about a possible oversupply of physicians. Today, however, most universities use an aptitude test to control the number of medical students.

What we can also see from Figure 1 and even more clearly from Table 1, the density of general practitioners started to decrease from $2002 \mathrm{on}$. As mentioned earlier, it is in 2002 when this measure of freezing new accreditations for physicians in private practice sites was introduced in entire Switzerland, and it is likely that this decrease is related to this policy intervention. However, this policy did not seem to affect specialists much, given that the number of specialists per 100,000 persons has steadily increased even after 2002.

In general, the Swiss political system grants a substantial amount of sovereignty to its 26 cantons. Because each is, among other things, responsible for its own health care system, it is rather difficult to implement a unified policy for them all, a fact which leads to additional heterogeneity among them. Figure 2 and Table 6 in the appendix show physician densities for all Swiss cantons in 2005. It is obvious that physician densities differ among the cantons and show a much higher variation for specialists. For general practitioners, densities vary between 33 and 63 physicians per 100,000 persons; for specialists the numbers lie between 54 and 327. Western and southern Switzerland account for the highest number of specialists. City cantons, e.g. Basel-Stadt (BS) and Geneva (GE), or cantons with university hospitals ${ }^{11}$ seem to attract more specialists.

In order to see the evolution of physician densities in the cantons over the time period considered, Figure 3 and Figure 4 report the relative changes in physician densities in \% from 1960 to $2005 .{ }^{12}$ As we can see from Figure 3, physician

10 The issue became a matter for public concern when the Council of Swiss Universities (Schweizerische Hochschulkonferenz) initiated a study, conducted by Gilliand and Eichenberger (1981), about future development of the physician population.

11 There is not a university in every Swiss canton. Six have a university hospital, i.e. Basel-Stadt (BS), Bern (BE), Fribourg (FR), Geneva (GE), Waadt (VD) and Zurich (ZH).

12 See Section 4 for a detailed data description. 
density of GPs decreased in 6 out of 26 cantons, but the number of specialists per 100,000 persons increased in all cantons, as Figure 4 shows. Also, the increases in specialists' densities are much larger than the ones for general practitioners. Obviously, the changes over time of physicians' densities for general practitioners and for specialists are driven at least partly by different mechanisms.

The different developments of generalists and specialists over time become apparent also by looking at Figure 5, where the share of general practitioners relative to the total number of physicians per canton in 1960 and 2005 is reported. In 1960, the share of general practitioners was higher than $50 \%$ in 18 out of 26 cantons. In 2005, however, in all but one canton the share of GPs is less than $40 \%$, and in the cantons of Geneva (GE) and Basel-Stadt (BS) this ratio has dropped even below $15 \%$.

In what follows, we outline the factors that are expected to be important determinants of the evolution of physician densities in Switzerland over time. We take into account a series of explanatory variables both derived from the demand for and the supply of physician services. In a next step, we are going to integrate these factors into an econometric model to explain the changes in physician densities' in the Swiss cantons over the last 45 years. 
Figure 2: Physician Densities in the Swiss Cantons in 2005

General practitioners' densities

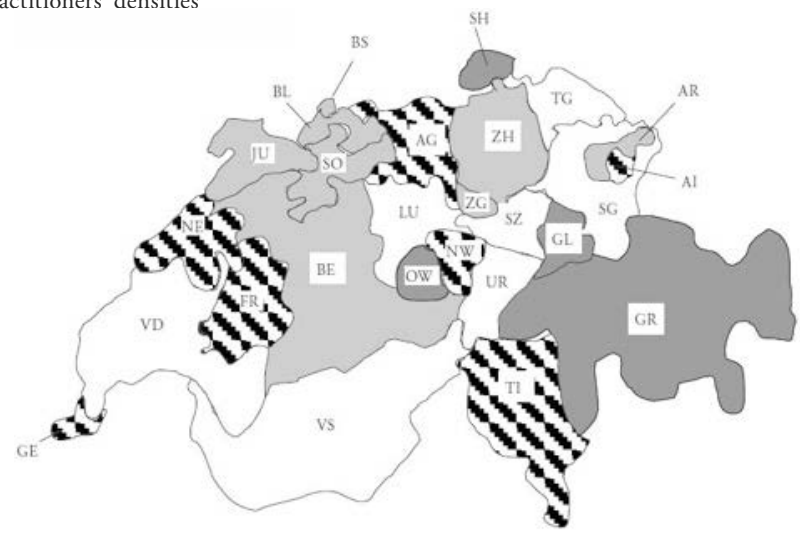

very high: $62-69$ physicians per 100,000 persons high: $\quad 53-61$ physicians per 100,000 persons low: $\quad 44-52$ physicians per 100,000 persons

very low: $35-43$ physicians per 100,000 persons

Specialists' densities

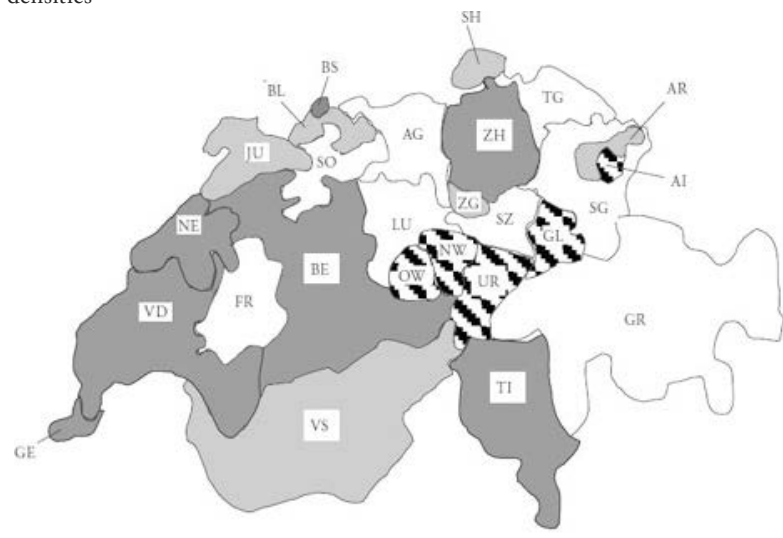

very high: $171-398$ physicians per 100,000 persons high: $\quad 141-170$ physicians per 100,000 persons low: $\quad 91-140$ physicians per 100,000 persons

[. very low: $56-90$ physicians per 100,000 persons 
Figure 3: Change in Physician Densities of General Practitioners in the Swiss Cantons from 1960 to 2005 (in \%)

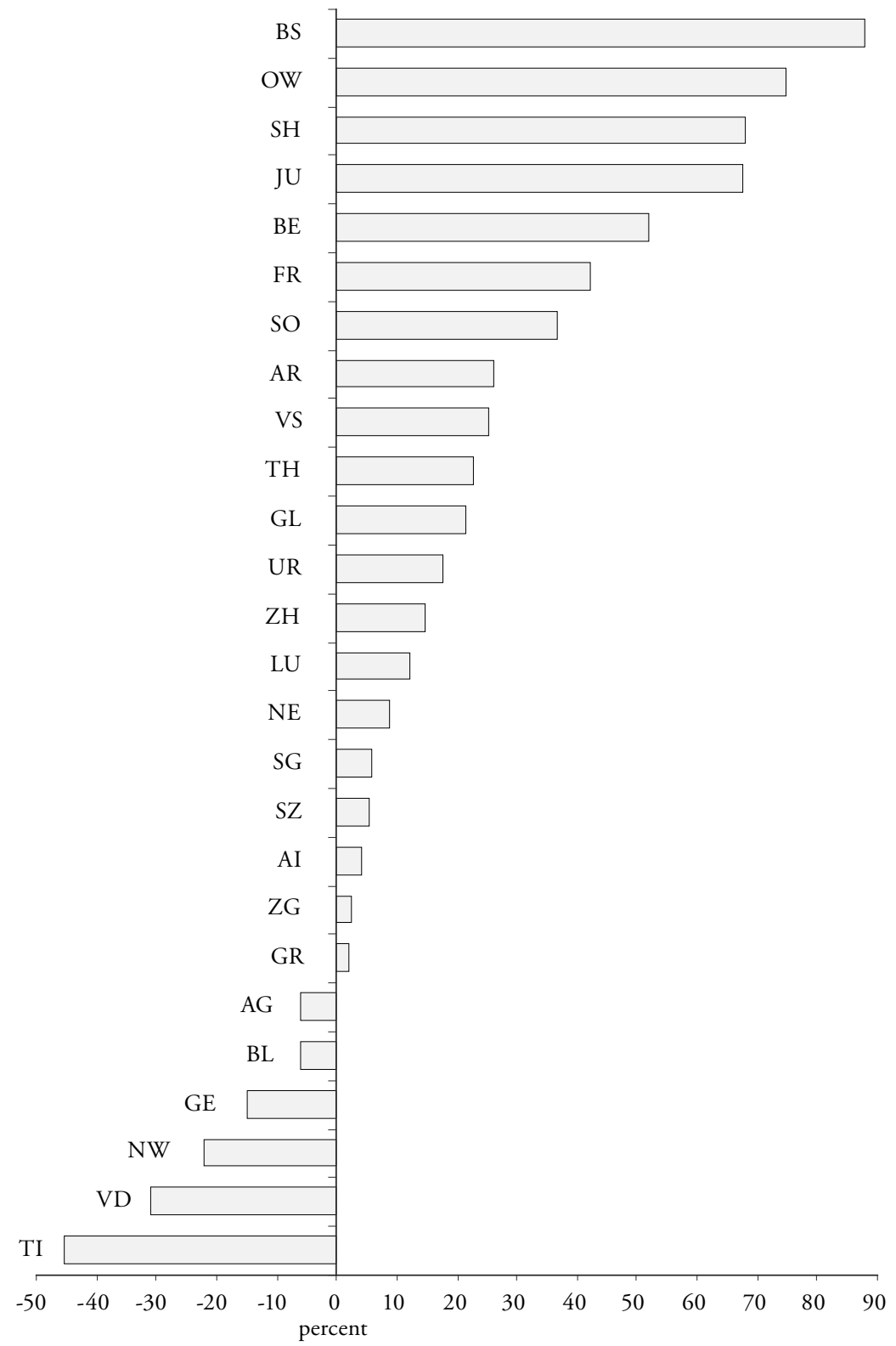


Figure 4: Change in Physician Densities of Specialists in the Swiss Cantons from 1960 to 2005 (in \%)

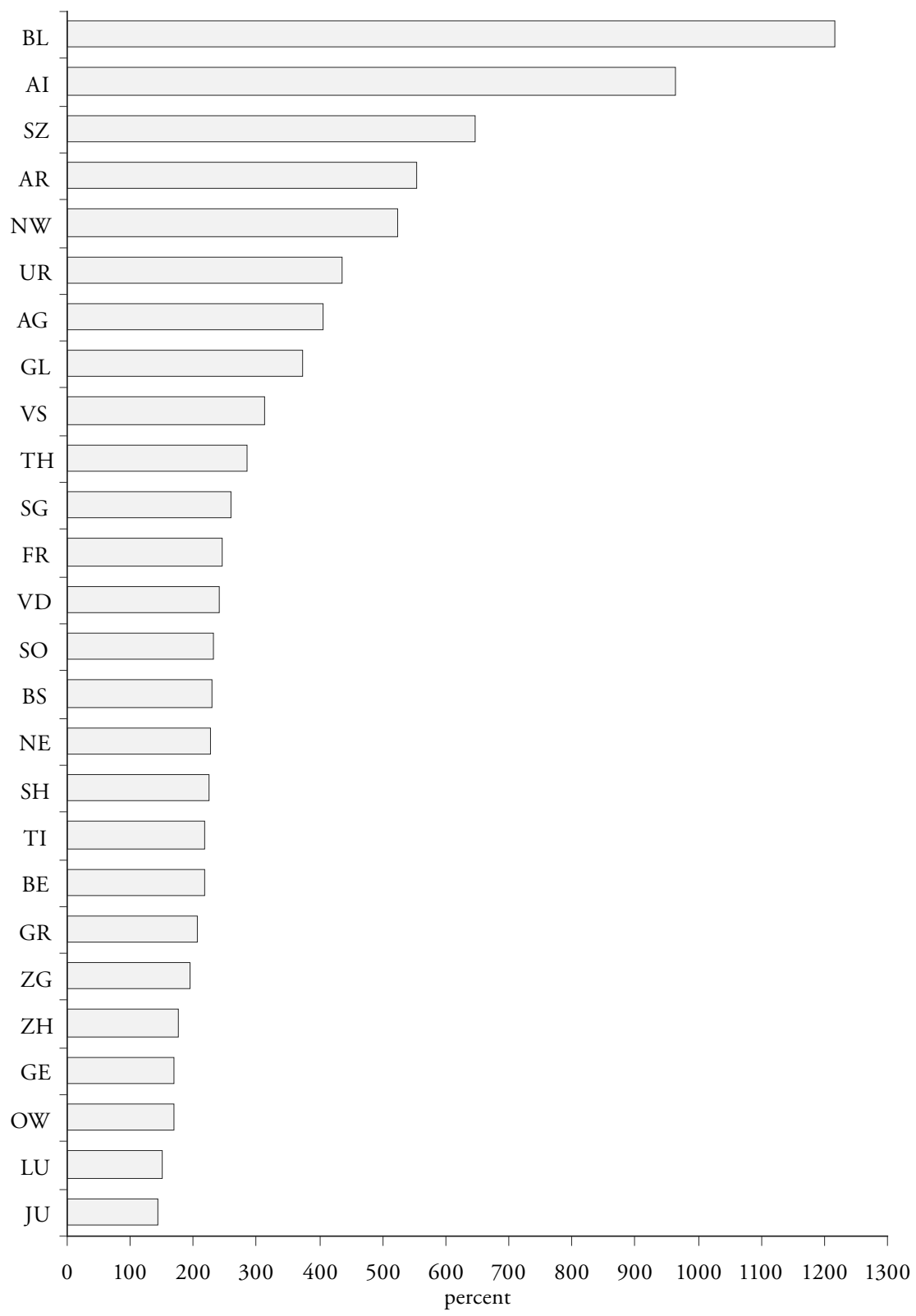


Figure 5: Share of General Practitioners (GPs) in 1960 and 2005 (Total of Physicians $=100 \%$ )

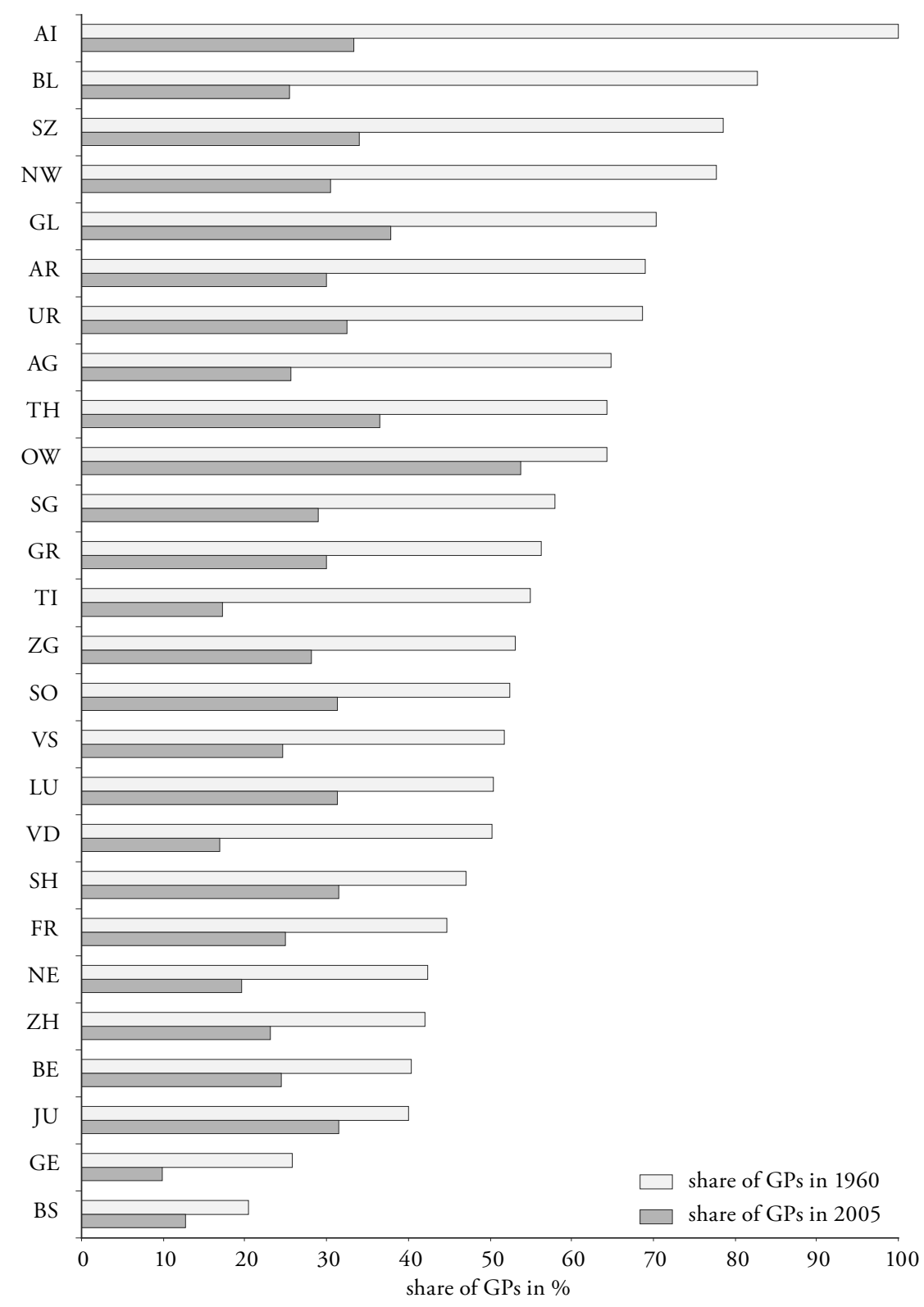




\section{Determinants of Physician Density}

\subsection{Determinants of Physician Densities across Regions}

The geographic distribution of physicians can be studied by analyzing the location choice process of physicians (see also Timmermans and Golledge, 1990). It is, however, often difficult to obtain direct information with which to determine the underlying processes. An indirect but more feasible way is to consider the aggregate outcome of these location decisions, i.e., to look at the distribution of physicians in different regions and to relate them to their determinants. According to Foster and GorR (1992), the main factors that affect the location of a physician's practice are the population in a region, the professional climate, the social environment, and market conditions. Also influencing the location choice of physicians are social amenities, such as educational facilities, entertainment and recreational opportunities, as well as shopping facilities. The better the social amenities, the more physicians are attracted to a region.

Based on Foster and Gorr (1992) and additional aspects derived from the relevant literature as outlined below, we describe the main factors that are expected to determine the growth rate of physician densities across the Swiss cantons over time. We take into account three sets of factors. The first set of determinants refers to the relative number of physicians that are already practicing in a certain area or canton and the division of work between the general practitioners and the specialists. We refer to these factors as saturation and substitution effects. The second set of factors provides a rough approximation of the demand for physician services related to the demographic and socio-economic characteristics of the population, i.e. the growth of the population, the per capita income and the average age. The third set of variables included in our analysis captures the medical infrastructure in a certain area, namely the number of hospital beds and the existence of a university hospital. In what follows, we outline the rationale for including the determinants and the expected effects on physician growth.

\section{a) Saturation and Substitution Effects}

Assuming that demand for physician services is bounded from above, i.e., physicians are unable to (infinitely) induce demand, we expect less growth in regions where physician density is already high. Also, inducing demand will be more difficult if density is already high. In fact, it might become less attractive for a new physician to open an additional practice site in a specific region where the supply of physicians reaches already a certain level (see, e.g., Foster and GorR, 1992). As a result of this saturation effect, a region's income potential and the number 
of practice opportunities for new physicians decrease. Therefore, new physicians no longer enter this market, but are more likely to open practices in regions with a lower level of physician density, and physicians then become more equally distributed. We model this saturation effect by including the lagged density of physicians into our model, and from this point of view, we expect the lagged density level to have a negative impact on physician growth in an area. Note that another effect might be additionally picked up by the lagged density variable. As mentioned above, the professional climate in a region is expected to affect a physician's location choice. The number of doctors in an area is one of several determinants of its professional climate. This effect might weaken the negative impact of the lagged density level on physician growth.

Another important factor that has to be taken into account is a possible substitution effect between the services of general practitioners and specialists. Specialists are typically multi-product firms, i.e., they not only provide special treatments, but also sell services normally delivered by general practitioners (see Newhouse et al., 1982). In order to see how the growth rates of the two physician types interact with each other, we include the lagged density value of both types, i.e., we model the physician growth of general practitioners as a function of the lagged density of general practitioners as well as of specialists, and vice versa for specialists. Due to the multi-product firm characteristic of specialists, we expect the lagged density level of specialists to have a negative impact on physician growth of general practitioners, and the lagged density of generalists to have no significant impact on the growth rate of specialist.

Given that compensation practices for physicians differ between the Swiss cantons, we add a variable for the income level of physicians to this category of saturation and substitution effects.

\section{b) Demand for Physician Services}

According to Foster and GorR (1992), the main factors that affect the location of a physician's practice are the population in a region, the professional climate, the social environment, and market conditions. A region's population is a direct measure of market size. Physicians are expected to be sensitive to changes in population growth. ${ }^{13}$ We expect the population growth rate to influence general practitioners and specialists differently. As mentioned earlier, specialists are typically multi-product firms, i.e., they not only provide special treatments, but also

13 Besides population growth, income and age there exist additional factors that may affect demand for physicians' services (e.g., increase in level of education, changing environmental factors like stress at work or pollution), which are not explicitly considered here. 
sell services normally delivered by general practitioners. Given that specialists are unique providers of certain services, they usually first settle in larger cities. Their ability to produce multiple services and in particular also those provided by general practitioners, allows them to compete to a certain extent with general practitioners. This substitution effect discourages general practitioners from settling in larger cities, which are typically characterized by higher population growth rates. Therefore, we expect $\overline{L . G P O P}$ to enter into the model with a positive sign for specialists and a negative sign for general practitioners (see Newhouse et al., 1982). It is, however, also possible that the higher demand of physician services can be satisfied by the existing providers. Given that we have no information on the capacity utilization, i.e., the amount of services provided by the doctors, we are unable to control for this possible effect.

Income per capita and its growth rate are additional variables that control for potential changes over time in the demand for physicians' services. Like most goods and services, healthcare is considered a normal good, where individuals consume larger amounts as their income rises. Therefore, we expect income and its growth rate to have a positive impact on physician growth. These expectations stand in line with several empirical studies that document a positive correlation between physician density and economic wellbeing (Copper et al., 2002; Koenig et al., 2003). As outlined by the U.S. Department of Health and Human Services (2006), there exist a few reasons why economic growth might fail increase physician requirements. Real per capita economic growth occurs through increased productivity. If physicians become more productive over time, their increased productivity will partially offset any increase in demand for physician services due to economic growth. In addition, economic growth allows individuals and communities to live healthier lives. Examples include improved diet, improved access to preventive medicine, and increased support for public health initiatives that might, in turn, reduce physician services. From these points of view, income and income growth may well have a negative impact on physician growth, and whether the total effect is positive or negative is an empirical question.

In addition to population growth and income, we include the age of the population and its growth rate over time as other important demand-side variables into our analysis. This is motivated by the well documented fact that demand for health services varies also with age (see, e.g., WagstafF, 1986). Given that the elderly use much greater levels of physician services relative to the non-elderly, both variables should have a positive effect on physician growth. This effect might be even stronger for specialists, because older people are also more likely to request specialists' services. 


\section{c) Medical Infrastructure}

The medical infrastructure, which includes sufficient access to hospitals and other medical facilities, is another important determinant of physician supply (Foster and GORR, 1992). Therefore, we include the number of hospital beds relative to the population and its growth rate over time as measures for the medical attractiveness of a canton into our analysis. As several empirical studies outline, the hospital bed density is positively correlated with the supply of physician services (e.g. Dartmouth Atlas Project, 2007). This holds in particular for specialists, who spend a good amount of their time on patients with chronic diseases and are more likely to require hospital services. The relationship between the number of hospital beds and physician supply is also often associated with the concept of supply-sensitive care, which refers to certain kinds of hospitalizations and the frequency of follow-up visits to specialists without having a strong clinical justification (Fisher and Wennberg, 2003). Given these arguments, we expect the hospital bed density and its growth rate to have a positive effect on specialists.

In addition to the hospital bed density, we take into account an additional factor that captures a region's medical attractiveness, namely whether there is a university hospital in the canton. Physicians might be attracted to regional facilities with outstanding reputations, which university hospital often have. This effect is expected to be particularly strong for specialists, who often provide complex services and are more likely to require the infrastructure of a university hospital. Furthermore, the inclusion of this variable accounts for potential differences in the cantons' policy measures, which may differ depending on the existence of a university with a medical faculty. Similarly to the hospital bed density, we expect the existence of a university hospital to have positive effect on the growth rate of specialists.

Finally, let us add a word of caution. In the context of geographic distribution of physicians, the issue of supplier-induced demand (SID) and the implicitly underlying market failure is often addressed. SID refers to the ability of physicians to generate demand in response to fee changes, declining market shares, or changes in labor-leisure relations (see, e.g., De Jaegher and Jegers, 2000). Academics as well as politicians disagree on its definition, and disagreement increases when talking about tests for providing empirical evidence and measuring SID (see, e.g., LABELLE et al., 1994). Our analysis does not face the complex issues of supplier-induced demand, mainly because we do not have the necessary data at hand. Therefore, we need to keep in mind that SID related aspects may play an additional role in explaining the regional evolution of physician densities over time, which, however, are not part of our analysis. 


\section{Empirical Model and Data Description}

Based on Foster and Gorr (1992) and our extensions discussed above, we estimate a simple model of physician growth and locational behavior in order to explain the evolution of physician density across the Swiss cantons over the last 45 years. In particular, we take into account the three sets of factors that are expected to affect the growth rate of physician density over time.

The empirical model is given by equations (1) and (2). The dependent variable physician growth $\overline{G P H Y S}$ is based on the growth rate of physicians from one period to another, and is expressed in \%. It is calculated by using a threeyear moving average of the yearly growth rates in order to smooth for annual variations.

The explanatory variables are the following ones. L.DENS is the physician density at the start of the period for which $\overline{G P H Y S}$ is calculated. In order to control for any substitution effects between physician services, we include the lagged physician densities of both types of physicians into the model. To allow for non-linearity, we additionally include the square of L.DENS into the estimation. INCOME PHYSICANS refers to an index of the average income of physicians with their own practice in 2003 and 2004 (average for Switzerland is set to 100). Note that there are no separate income data available for general practitioners and specialists. Also, due to the lack of yearly income figures we have to approximate the income situation per canton by the respective index value, keeping in mind that it is only a rough, but probably still the best possible approximation. ${ }^{14}$

$\overline{\text { L.GROWTH POP }}$ refers to the population growth, expressed in $\%$, and is calculated again by using a three-year moving average and by taking the lagged value. INCOME refers to the real income per capita in each canton. CHANGE $I N C O M E$ is the growth rate of the real income per capita from the past to the current year and is expressed in \%. $A G E$ captures the average age of the population. Given that data are available from 1980 on only, the variable $A G E$ is the mean of the average age over the years available. GROWTH AGE refers to the growth rate of the average age from 1980 to the latest year in our data and is expressed in $\%$.

HOSPITAL BEDS is the number of hospital beds per 1,000 inhabitants. Given that data are available from 1998 on only, the variable HOSPITAL BEDS is the mean of the average number of beds per 1,000 inhabitants over the years

14 We also considered including the growth rate of physicians' income. However, the growth rate is highly correlated with the physicians' income level, which also indicates that the ranking of cantons in terms of physicians' income has remained rather stable over the years considered. 
available. Similarly, GROWTH HOSPITAL BEDS refers to the growth rate of the hospital bed density over from 1998 up to the latest year in our data. Finally, $M E D U N I$ is a dummy variable taking the value of one if the canton has a university hospital, and zero else. In Switzerland, six cantons have a university hospital, namely Basel-Stadt (BS), Bern (BE), Fribourg (FR), Geneva (GE), Waadt (VD) and Zurich (ZH).

We also include a yearly dummy variable $\left(D_{t}\right)$ as another explanatory variable to pick up other year-specific effects. $D_{t}$ takes on the value of one if $t^{\prime}=t$, otherwise zero. We investigate the different effects separately for general practitioners and specialists, as shown by (1) and (2), repectively.

$$
\begin{aligned}
& \begin{aligned}
\overline{G P H Y S}_{G E N i t}= & \alpha_{1}+\alpha_{2} L \cdot D E N S_{G E N i t}+\alpha_{3} L \cdot D E N S_{G E N i t}{ }^{2} \\
& +\alpha_{4} L \cdot D E N S_{S P E i t}+\alpha_{5} L \cdot D E N S_{\text {SPEit }}^{2}
\end{aligned} \\
& +\alpha_{6} \text { INCOME PHYSICIANS }_{i} \\
& +\alpha_{7} \overline{L . G P O P}_{i t}+\alpha_{8} I_{N C O M E_{i t}} \\
& +\alpha_{9} \text { CHANGE INCOME } \\
& +\alpha_{10} A G E_{i}+\alpha_{11} \text { CHANGE } A G E_{i} \\
& +\alpha_{12} \text { HOSPITALBEDS }_{i} \\
& +\alpha_{13} \text { CHANGE HOSPITALBEDS } \\
& +\alpha_{14} M^{2} D U N I_{i} \\
& +\sum \gamma_{t^{\prime}} D_{t^{\prime}}+\varepsilon_{i t} \\
& \overline{\text { GPHYS }}_{\text {SPEit }}=\alpha_{1}+\alpha_{2} \text { L.DENS }_{\text {GENit }}+\alpha_{3} \text { L.DENS }_{\text {GENit }}{ }^{2} \\
& +\alpha_{4} L^{2} . D E N S_{\text {SPEit }}+\alpha_{5} L_{\text {L.DENS }}{ }_{\text {SPEit }}^{2} \\
& +\alpha_{6} \text { INCOME PHYSICIANS }_{i} \\
& +\alpha_{7} \overline{L . G P O P}_{i t}+\alpha_{8} \text { INCOME }_{i t} \\
& +\alpha_{9} \text { CHANGE INCOME } \\
& +\alpha_{10} A G E_{i}+\alpha_{11} \text { CHANGE } A G E_{i} \\
& +\alpha_{12} \text { HOSPITALBEDS }_{i} \\
& +\alpha_{13} \text { CHANGE HOSPITALBEDS } \\
& +\alpha_{14} M^{2} D U N I_{i} \\
& +\sum \gamma_{t^{\prime}} D_{t^{\prime}}+\varepsilon_{i t}
\end{aligned}
$$

where $G E N=$ general practitioner, $S P E=$ specialist $, i=1, \ldots, 26, t, t^{\prime}=$ $1960, \ldots, 2001$. 
Note that we estimate equations (1) and (2) with data up to the year 2001 only, even though our sample includes observations up to 2005. We choose this procedure to properly investigate potential effects of freezing new accreditations for physicians in private practice sites, which was introduced in 2002, and to allow for the possibility that this 'physician stop' might have affected location decisions of physicians. To take into account this policy measure and potential implications for physician density figures, we specify an interaction model where we use the dummy variable $D_{\text {STOP }}$ as additional explanatory variable. The dummy variable $D_{\text {STOP }}$ takes the value of one for the years 2002 to 2005, i.e., when this policy measure was in place, and zero else. We interact this dummy variable $D_{\text {STOP }}$ with all the right hand side variables except the constant, and we include these interaction terms as additional determinants in our model. This allows us to see whether and how this policy measure (or at least what happened after 2002) has affected the various determinants of physician density and their combined effects on physician growth. Due to space restrictions, we abstain from writing out the model, to which we refer as interaction model.

Given that our data spread out over a long time period, we specify an additional extension to our basic model that allows us to estimate time-varying parameters of the lagged density variables. For this purpose, we multiply L.DENS for both physician types with the yearly dummy variable $\left(D_{t^{\prime}}\right)$. The coefficients of the interaction terms then capture the yearly effects of the lagged density variables on physician growth. The other variables are defined as in equations (1) and (2). This extended model is described by equations (3) and (4) and is estimated with the data over the entire time period from 1960 up to 2005.

$$
\begin{aligned}
\overline{\text { GPHYS }}_{\text {GENit }}= & \alpha_{1}+\sum \eta_{t^{\prime}} \text { L.DENS }_{\text {GENit }} D_{t^{\prime}}+\sum \lambda_{t^{\prime}} \text { L.DENS }_{\text {SPEEit }_{i t} D_{t^{\prime}}} \\
& +\alpha_{6} \text { INCOME PHYSICIANS }_{i} \\
& +\alpha_{7} \overline{L . G P O P}_{i t}+\alpha_{8} \text { INCOME }_{i t} \\
& +\alpha_{9} \text { CHANGE INCOME }_{i t} \\
& +\alpha_{10} \text { AGE }_{i}+\alpha_{11} \text { CHANGE AGE }_{i} \\
& +\alpha_{12} \text { HOSPITALBEDS }_{i} \\
& +\alpha_{13} \text { CHANGE HOSPITALBEDS }_{i} \\
& +\alpha_{14} \text { MEDUNI }_{i} \\
& +\sum \gamma_{t^{\prime}} D_{t^{\prime}}+\varepsilon_{i t}
\end{aligned}
$$




$$
\begin{aligned}
\overline{\text { GPHYS }}_{\text {SPEit }}= & \alpha_{1}+\sum \eta_{t^{\prime}} \text { L.DENS }_{\text {GENit }} D_{t^{\prime}}+\sum \lambda_{t^{\prime}} \text { L.DENS }_{\text {SPEEt } D_{t^{\prime}}} \\
& +\alpha_{6} \text { INCOME PHYSICIANS }_{i} \\
& +\alpha_{7} \overline{L . G P O P}_{i t}+\alpha_{8} \text { INCOME }_{i t} \\
& +\alpha_{9} \text { CHANGE INCOME }_{i t} \\
& +\alpha_{10} \text { AGE }_{i}+\alpha_{11} \text { CHANGE AGE }_{i} \\
& +\alpha_{12} \text { HOSPITALBEDS }_{i} \\
& +\alpha_{13} \text { CHANGE HOSPITALBEDS }_{i} \\
& +\alpha_{14} \text { MEDUNI }_{i} \\
& +\sum \gamma_{t^{\prime}} D_{t^{\prime}}+\varepsilon_{i t}
\end{aligned}
$$

where $i=1, \ldots, 26, t, t^{\prime}=1960, \ldots, 2005$.

Our sample comprises annual data for the number of physicians in the 26 cantons of Switzerland over the period from 1960 to 2005. After having eliminated observations for which some of the variables are missing, we have a total of 966 observations, and the data include physicians working in a practice as general practitioners or as specialists. Also, due to the construction of the lagged moving average growth variables included in our model, our final sample does not contain yearly observations for the years 1960,1961, 1962 and 2005. The panel is not balanced, since physician data for the two split cantons Nidwalden and Obwalden are not available before 1967. Furthermore, the canton Jura was only created in 1978; it had previously been a part of the canton Bern. Also, assistant doctors and specialists working exclusively in hospitals are not included in the data. ${ }^{15}$

The data are provided by the Swiss Federal Statistical Office with the exception of the income information of physicians, which are available from the Swiss Medical Association FMH (see Hasler and Reichert, 2008). Note that not all variables are available for all the years. If this is the case, we were forced to build average values. The details are described in Table 2 , which summarizes the definition of our variables.

Table 3 shows some descriptive statistics of the variables used in our regression analysis. As is already discussed in Section 2, where we describe the evolution of physician density in the 26 Swiss cantons over the last 45 years, the number of specialists has on average grown at a much higher rate than that of general practitioners over the time period considered. As a result, physician density is also

15 The fact that the data includes only physicians having their own practice site is not expected to be a serious shortcoming since most hospitals are public, and decisions about employment opportunities for physicians in hospitals are, therefore, outside the doctors' control. 
Table 2: Definition of Variables

\begin{tabular}{|c|c|}
\hline Variable & Description \\
\hline$i$ & Index of canton: $i=1, \ldots, 26$ \\
\hline$t, t^{\prime}$ & Year of observation: $t, t^{\prime}=1960, \ldots, 2005$ resp. up to 2001 \\
\hline$G P H Y S_{G E N i t}$ & Physician growth of general practitioners in $\%$ \\
\hline$\overline{G P H Y S}_{G E N i t}$ & $\begin{array}{l}\text { 3-year moving average of physician } \\
\text { growth of general practitioners in } \% \text {, i.e., } \\
\left(G P H Y S_{G E N i t-1}+G P H Y S_{G E N i t}+G P H Y S_{G E N i t+1}\right) / 3\end{array}$ \\
\hline$G P H Y S_{\text {SPEit }}$ & Physician growth of specialists in $\%$ \\
\hline$\overline{G P H Y S}_{\text {SPEit }}$ & $\begin{array}{l}\text { 3-year moving average of physician growth in } \% \\
\left(\text { GPHYS }_{\text {SPEit-1 }}+\text { GPHYS }_{\text {SPEit }}+G P H Y S_{\text {SPEit }+1}\right) / 3\end{array}$ \\
\hline L.DENS $S_{G E N i t}$ & $\begin{array}{l}\text { Lagged physician density of general practitioners (number of } \\
\text { general practitioners for } 100,000 \text { persons) }\end{array}$ \\
\hline L.DENS $S_{\text {SPEit }}$ & $\begin{array}{l}\text { Lagged physician density of specialists (number of specialists } \\
\text { for } 100,000 \text { persons) }\end{array}$ \\
\hline$\overline{L . G R O W T H P O P}_{i t}$ & Lagged 3-year moving average of population growth in $\%$ \\
\hline$I N C O M E_{i t}$ & $\begin{array}{l}\text { Real income per capita (in 1,000) (deflated with the Consumer } \\
\text { Price Index and expressed in CHF of 2005) }\end{array}$ \\
\hline GROWTH INCOME $E_{i t}$ & Change in the real income per capita from in $\%$ \\
\hline$A G E_{i}$ & $\begin{array}{l}\text { Average age of population, average over the period from } 1980 \\
\text { to } 2005 \text { ( } 2001 \text { resp.) }\end{array}$ \\
\hline GROWTH $A G E_{i}$ & $\begin{array}{l}\text { Change in average age of population from } 1980 \text { to } 2005 \text { (resp. } \\
\text { 2001) in \% }\end{array}$ \\
\hline HOSPITAL BEDS $_{i}$ & $\begin{array}{l}\text { Number of hospital beds for } 1,000 \text { persons, average over the } \\
\text { period from } 1998 \text { to } 2005 \text { (resp. 2001) }\end{array}$ \\
\hline GROWTH HOSPITAL BEDS & $\begin{array}{l}\text { Change in the number of hospital beds for } 1,000 \text { persons from } \\
1998 \text { to } 2005 \text { (resp. 2001) in \% }\end{array}$ \\
\hline$M E D U N I_{i}$ & $\begin{array}{l}\text { Dummy variable }=1 \text { if canton has a university hospital, } \\
=0 \text { else }\end{array}$ \\
\hline INCOME PHYSICIANS $_{i}$ & $\begin{array}{l}\text { Income of physicians (in 1,000), average over the years } 2003 \\
\text { and } 2004\end{array}$ \\
\hline$D_{t}$ & Dummy variable $=1$ if $t=t^{\prime},=0$ else \\
\hline$D_{S T O P}$ & Dummy variable $=1$ if $t>2001,=0$ else \\
\hline
\end{tabular}


higher for specialists. At the same time, the distribution of specialists seems to be more unequal. On average, the population grew $0.65 \%$ from one year to the other, and the average age increased by $12 \%$ over the time period considered. Looking at the number of hospital beds per 1,000 inhabitants, we observe that this figure decreased over the time period from 1998 to 2005, on average. However, this does not hold for all cantons.

Table 3: Descriptive Statistics (1960 to 2005)

\begin{tabular}{lrccc}
\hline Variable & Mean & Std. Dev. & Min & Max \\
\hline$\overline{\text { GPHYS }}_{G N N}$ & 1.03 & 3.517 & -19.811 & 14.479 \\
& 3.292 & 3.965 & -12.322 & 32.162 \\
$\overline{G P H Y S}_{S P E}$ & 49.083 & 13.385 & 18.684 & 84.639 \\
L.DENS $_{G E N}$ & 71.861 & 48.351 & 7.313 & 294.152 \\
L.DENS $_{\text {SPE }}$ & 0.640 & 1.278 & -16.164 & 4.909 \\
L.GROWTHPOP $_{\text {INCOME }}$ & 22.824 & 18.221 & 1.386 & 106.327 \\
GROWTH INCOME & 8.078 & 6.731 & -16.180 & 42.512 \\
AGE & 37.996 & 1.583 & 35.918 & 42.716 \\
GROWTH AGE & 12.004 & 4.626 & 4.119 & 19.853 \\
HOSPITAL BEDS & 5.959 & 2.363 & 2.431 & 13.146 \\
GROWTH HOSPITAL BEDS & -11.738 & 9.815 & -33.713 & 6.439 \\
MEDUNI & 0.261 & & 0 & 1 \\
INCOME PHYSICIANS & 102.165 & 13.207 & 76.1 & 129.9 \\
\hline
\end{tabular}

\section{Analysis and Results}

We estimate the empirical models as outline above by applying different estimation techniques to check for the robustness of our results. The GLS estimation (A) with heteroscedastic error structure and cross-sectional correlation allows for differences in the variance as well as a correlation among the 26 cantons. The GLS estimation (B) relaxes not only the assumption of no cross-sectional correlation, but of no autocorrelation as well. Finally, the fixed effect model estimation (C) controls for unobserved heterogeneity across the cantons. Given that our sample includes all cantons in Switzerland and is therefore not a random sample, the 
fixed effects model specification is appropriate. In addition, from the results of a modified version of the Durbin-Watson test, we allow the disturbance term to follow an AR(1) process (see also Bhargave et al., 1982). Note that the constant term of the fixed effects estimations also captures the effects of the time-invariant variables that can be included in the GLS estimations only.

Table 4 reports the estimation results of the simple model for the time period up to 2001, as given by equations (1) and (2). Let us start with the saturation and substitution effects, which are captured by the lagged density variables and the physician income. For the general practitioners, the lagged value of their own density level is not statistically significant and negative, which means that we do not find evidence for the expected saturation effect, i.e. an already high density of general practitioners does not have a significantly negative effect on their growth rate. Similarly, the squared density level of GPs is not significant. When looking at the results of the extended model as given by equations (3) and (4), where we estimate time-varying coefficients for the lagged density level, however, we find negative and significant coefficients in 22 out of the 43 years. The yearly coefficients are reported in Figure 6, from which we also see that the different estimation methods provide quite similar results for most of the years in the extended model. ${ }^{16}$

As to the substitution effects between GPs and specialists, the coefficient of L.DENS $S_{\mathrm{SPE}}$ is negative for all three estimation methods and statistically significant for the two GLS estimations. This means that a higher density level of specialists in the former year has a negative impact on the growth rate of general practitioners, and we interpret this as evidence for specialists being able to substitute services provided by general practitioners. The existence of a substitution effect becomes even more visible when looking at the extended model with the yearly estimated coefficients of $L . D E N S_{\mathrm{SPE}}$. As is outlined in Figure 7, the yearly coefficients of $L . D E N S_{\mathrm{SPE}}$ are negative in most of the years, and they are also statistically significant in all but seven years.

When looking at the specialists, whose results are reported in the most rightward columns of Table 4, the density level of general practitioners in an area does not seem to affect the growth rate of specialist. In contrast, a higher density level of specialists in the former year has a negative and significant impact on their own growth rate, at least for the GLS estimations. This observation stands in line with our expectations of a saturation effect as outlined in Section 3.1. Specialists are discouraged to enter a new region where the density of specialists is already

16 In order to save space, we only report selected results of the extended model. 
Figure 6: Estimated Paths of L.DENSGEN Coefficients for General Practitioners in the Extended Model (1960-2005)

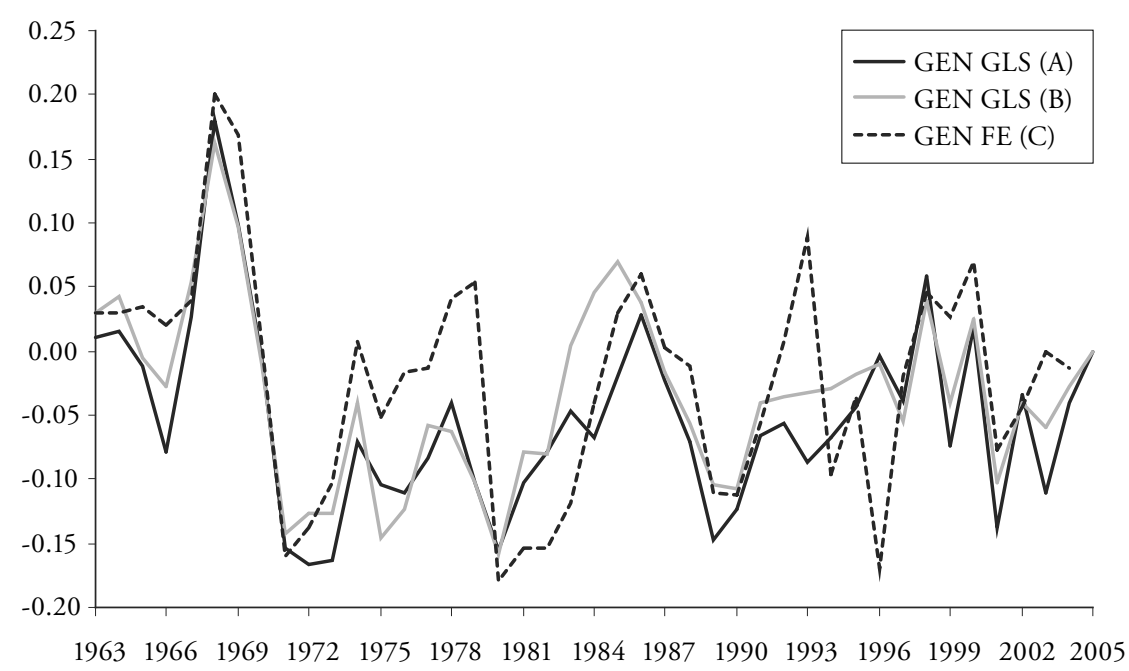

Figure 7: Estimated paths of L.DENSSPE Coefficients for General Practitioners in the Extended Model (1960-2005)

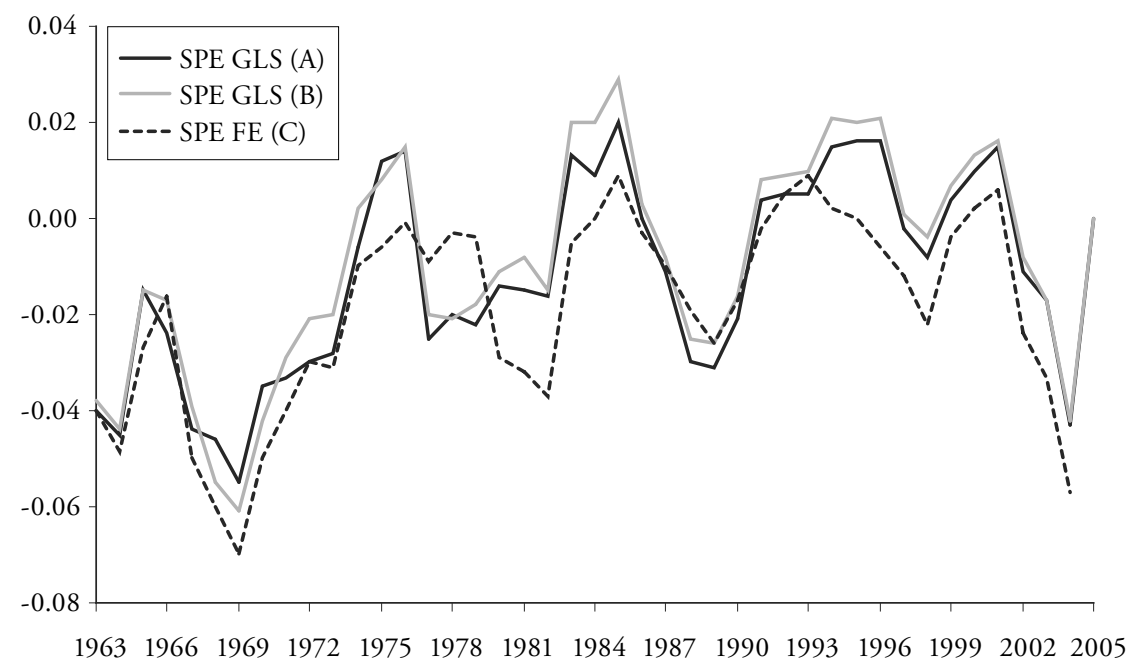


high. We can see this effect even better when looking again at the results of our extended model with the time-varying lagged density coefficients. As can be seen from Figure 8, the estimated coefficients of $L . D E N S_{\mathrm{SPE}}$ are negative in almost all of the years, and they are also statistically significant. The positive coefficient of the squared density level of specialists additionally tells us that this effect is nonlinear, i.e. the negative effect becomes more positive with higher density levels. However, the coefficient of the squared density level is only significant for the GLS estimations and also very small.

Figure 8: Estimated Paths of L.DENSSPE Coefficients for Specialists in the Extended Model (1960-2005)

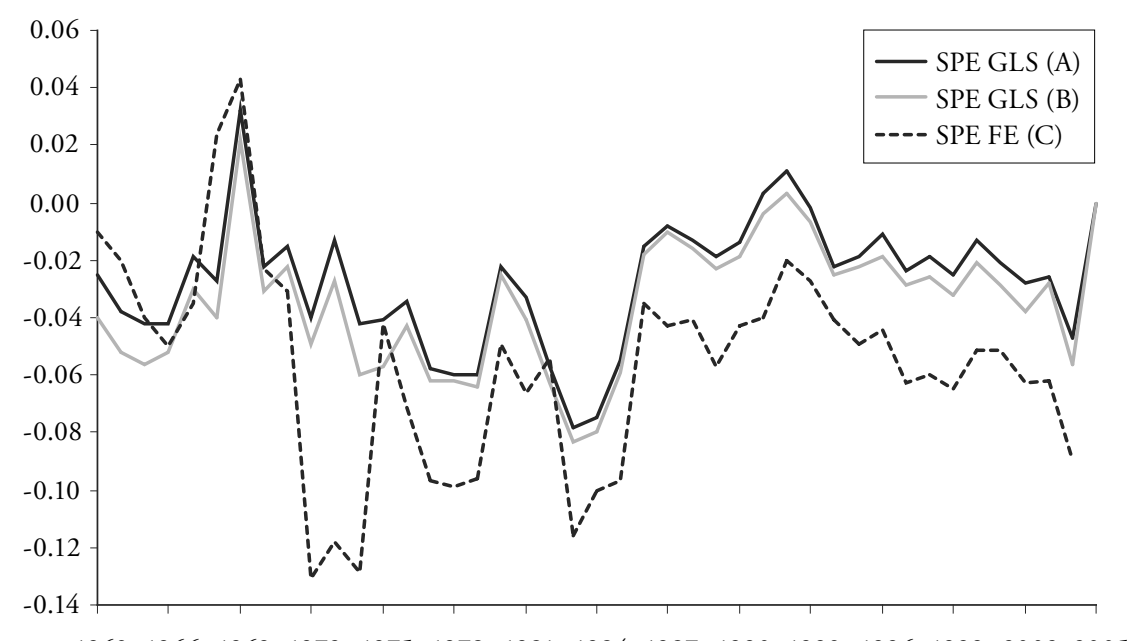

$\begin{array}{lllllllllllllll}1963 & 1966 & 1969 & 1972 & 1975 & 1978 & 1981 & 1984 & 1987 & 1990 & 1993 & 1996 & 1999 & 2002 & 2005\end{array}$

As to the physician income, which measures the income level of physician compensation in the Swiss cantons, we observe a negative, even though not always significant effect on physician growth rate for both general practitioners and specialists. For the latter group, the negative impact is even stronger. Even though the variable is only a rough approximation of the physician income, the negative correlation may at least partly reflect a certain saturation effect, i.e., the stronger the physician growth, the worse are the income prospects in an area. Note, however, that this variable was rather included to control for the different compensation 
schemes across the Swiss cantons than to measure a possible income effect, which, would definitively require more accurate income data. ${ }^{17}$

The factors related to the demand for physician services have the following effects. The population growth of former periods $\overline{L . G P O P}$ negatively affects the growth of general practitioners, but has a positive effect on specialists' growth rate, which, however, is statistically significant for estimation method (A) only. We interpret the differences between GPs and specialists, and in particular the negative effect of population changes on the growth rate of general practitioners, as additional evidence for a substitution effect between the two physician types.

INCOME has no significant effect on physician growth over time. In contrast, the yearly growth rate of income has a positive effect on the growth rate of general practitioners, but this holds only for the fixed effects estimation. The result provides evidence for a positive income effect on the demand for health services. In the case of specialist, however, the effect of income growth is negative and significant in two out of three estimations. As mentioned in Section 3.1., such a negative effect can be explained by a productivity effect as well as by the fact that economic growth allows individuals and communities to live healthier lives. This might also explain the differences between general practitioners and specialist, with the latter more likely to treat more seriously ill patients.

The average age of the population $A G E$ as well as the changes over time GROWTH AGE both have a positive and significant effect on the growth rate of specialist, but do not affect the general practitioners. The stronger effect for specialists may be due to the fact that older people are also more likely to request specialists' services.

Finally, let us consider the medical infrastructure variables. The number of hospital beds per 1,000 inhabitants does not seem to affect the growth rates of both general practitioners and specialists. In contrast to the level, the changes over time have a positive impact on the growth rate of specialists. In the case of general practitioners, the coefficient is negative, but only significant in one out of two cases. As to MEDUNI, it also positively affects the specialists' growth rate, but has no significant effect on the growth rate of general practitioners. A higher number of hospital beds and the presence of a university hospital seem to increase the medical attractiveness of an area for specialists. The observation that

17 Note that we do not report any results for the fixed effects estimation, since INCOME PHYSICIANS is constant over time and therefore dropped. The same holds for the age, the hospital bed and the MEDUNI variables. 
general practitioners are less sensitive to these factors can be explained by fact that specialists are more likely to use this type of medical infrastructure.

Overall, we conclude that general practitioners and specialists react at least partly in different ways to the main determinants of physician density and their changes over time. In particular, an already high level of specialists in a canton seems to discourage other specialists to open a new practice site. Also, generalists seem to avoid areas where the density of specialist is higher, which is evidence for substitution of services between the two physician types. This substitution effect, however, goes only in one direction, i.e., the growth of specialists is not sensitive to the density level of general practitioners. Finally, our model specification provides a better fit for general practitioners compared to the specialists.

Table 4: Physician Growth in the Simple Model (1960-2001)

\begin{tabular}{|c|c|c|c|c|c|c|}
\hline \multirow[b]{3}{*}{ Variable $^{c}$} & \multicolumn{3}{|c|}{ General practitioners } & \multicolumn{3}{|c|}{ Specialists } \\
\hline & \multicolumn{2}{|c|}{$\mathrm{GLS}^{\mathrm{a}}$} & \multirow{2}{*}{$\begin{array}{l}\text { Fixed } \\
\text { Effect }^{b} \\
\text { (C) }\end{array}$} & \multicolumn{2}{|c|}{$\mathrm{GLS}^{\mathrm{a}}$} & \multirow{2}{*}{$\begin{array}{l}\text { Fixed } \\
\text { Effect }^{\mathrm{b}} \\
\text { (C) }\end{array}$} \\
\hline & (A) & (B) & & (A) & (B) & \\
\hline L.DENS_GEN & $\begin{array}{c}-0.013 \\
(0.032)\end{array}$ & $\begin{array}{c}-0.005 \\
(0.055)\end{array}$ & $\begin{array}{r}0.042 \\
(0.101)\end{array}$ & $\begin{array}{c}-0.014 \\
(0.022)\end{array}$ & $\begin{array}{c}0.061 \\
(0.041)\end{array}$ & $\begin{array}{l}0.393^{* * *} \\
(0.132)\end{array}$ \\
\hline$L . D E N S_{-} G E N^{2}$ & $\begin{array}{c}-0.000 \\
(0.000)\end{array}$ & $\begin{array}{c}-0.000 \\
(0.000)\end{array}$ & $\begin{array}{c}-0.001 \\
(0.001)\end{array}$ & $\begin{array}{c}0.000 \\
(0.000)\end{array}$ & $\begin{array}{c}-0.001 \\
(0.000)\end{array}$ & $\begin{array}{c}-0.003^{* *} \\
(0.001)\end{array}$ \\
\hline L.DENS_SPE & $\begin{array}{c}-0.012^{* *} \\
(0.005)\end{array}$ & $\begin{array}{c}-0.018^{* *} \\
(0.008)\end{array}$ & $\begin{array}{c}-0.017 \\
(0.031)\end{array}$ & $\begin{array}{l}-0.070^{* * *} \\
(0.004)\end{array}$ & $\begin{array}{c}-0.054^{* * *} \\
(0.009)\end{array}$ & $\begin{array}{c}-0.057 \\
(0.041)\end{array}$ \\
\hline L.DENS_SPE ${ }^{2}$ & $\begin{array}{l}0.000^{* * *} \\
(0.000)\end{array}$ & $\begin{array}{l}0.000^{* * *} \\
(0.000)\end{array}$ & $\begin{array}{c}0.000 \\
(0.000)\end{array}$ & $\begin{array}{l}0.000^{* * *} \\
(0.000)\end{array}$ & $\begin{array}{l}0.000^{* * *} \\
(0.000)\end{array}$ & $\begin{array}{c}0.000 \\
(0.000)\end{array}$ \\
\hline INCOME PHYSICIANS & $\begin{array}{r}-0.006^{*} \\
(0.004)\end{array}$ & $\begin{array}{c}-0.009 \\
(0.009)\end{array}$ & - & $\begin{array}{c}-0.009^{* * *} \\
(0.003)\end{array}$ & $\begin{array}{c}-0.012 \\
(0.011)\end{array}$ & - \\
\hline$\overline{\text { L.GROWTHPOP }}$ & $\begin{array}{c}-0.508^{* * *} \\
(0.049)\end{array}$ & $\begin{array}{c}-0.185^{* * *} \\
(0.060)\end{array}$ & $\begin{array}{c}-0.307^{* * *} \\
(0.103)\end{array}$ & $\begin{array}{l}0.115^{* *} \\
(0.051)\end{array}$ & $\begin{array}{c}0.035 \\
(0.090)\end{array}$ & $\begin{array}{c}-0.039 \\
(0.144)\end{array}$ \\
\hline INCOME & $\begin{array}{c}0.001 \\
(0.010)\end{array}$ & $\begin{array}{c}0.010 \\
(0.012)\end{array}$ & $\begin{array}{c}0.012 \\
(0.048)\end{array}$ & $\begin{array}{c}0.009 \\
(0.006)\end{array}$ & $\begin{array}{c}0.002 \\
(0.018)\end{array}$ & $\begin{array}{c}0.084 \\
(0.059)\end{array}$ \\
\hline GROWTH INCOME & $\begin{array}{c}-0.025 \\
(0.017)\end{array}$ & $\begin{array}{c}0.001 \\
(0.014)\end{array}$ & $\begin{array}{l}0.078^{* *} \\
(0.035)\end{array}$ & $\begin{array}{c}-0.043^{* * *} \\
(0.009)\end{array}$ & $\begin{array}{c}-0.061^{* * *} \\
(0.013)\end{array}$ & $\begin{array}{r}-0.079 \\
(0.051)\end{array}$ \\
\hline$A G E$ & $\begin{array}{c}-0.028 \\
(0.041)\end{array}$ & $\begin{array}{c}-0.010 \\
(0.082)\end{array}$ & - & $\begin{array}{l}0.374^{* * *} \\
(0.043)\end{array}$ & $\begin{array}{l}0.271^{* *} \\
(0.109)\end{array}$ & - \\
\hline GROWTH AGE & $\begin{array}{c}-0.013 \\
(0.015)\end{array}$ & $\begin{array}{c}0.009 \\
(0.032)\end{array}$ & - & $\begin{array}{l}0.136^{* * *} \\
(0.013)\end{array}$ & $\begin{array}{l}0.111^{* *} \\
(0.044)\end{array}$ & - \\
\hline HOSPITAL BEDS & $\begin{array}{c}0.017 \\
(0.034)\end{array}$ & $\begin{array}{c}-0.073 \\
(0.066)\end{array}$ & - & $\begin{array}{c}0.020 \\
(0.039)\end{array}$ & $\begin{array}{c}0.087 \\
(0.102)\end{array}$ & - \\
\hline
\end{tabular}




\begin{tabular}{|c|c|c|c|c|c|c|}
\hline \multirow[b]{3}{*}{ Variable $^{c}$} & \multicolumn{3}{|c|}{ General practitioners } & \multicolumn{3}{|c|}{ Specialists } \\
\hline & \multicolumn{2}{|c|}{$\mathrm{GLS}^{\mathrm{a}}$} & \multirow{2}{*}{$\begin{array}{l}\text { Fixed } \\
\text { Effect }^{\mathrm{b}} \\
\text { (C) }\end{array}$} & \multicolumn{2}{|c|}{$\mathrm{GLS}^{\mathrm{a}}$} & \multirow{2}{*}{$\begin{array}{l}\text { Fixed } \\
\text { Effect }^{\mathrm{b}} \\
\text { (C) }\end{array}$} \\
\hline & (A) & (B) & & (A) & (B) & \\
\hline GROWTH HOSPITAL BEDS & $\begin{array}{c}-0.012^{* *} \\
(0.005)\end{array}$ & $\begin{array}{c}-0.016 \\
(0.012)\end{array}$ & - & $\begin{array}{l}0.035^{* * *} \\
(0.006)\end{array}$ & $\begin{array}{l}0.031^{* *} \\
(0.013)\end{array}$ & - \\
\hline MEDUNI & $\begin{array}{c}-0.047 \\
(0.118)\end{array}$ & $\begin{array}{c}0.160 \\
(0.212)\end{array}$ & - & $\begin{array}{l}1.170^{* * *} \\
(0.094)\end{array}$ & $\begin{array}{l}1.151^{* * *} \\
(0.320)\end{array}$ & - \\
\hline Constant & $\begin{array}{l}5.259^{* * *} \\
(1.460)\end{array}$ & $\begin{array}{c}3.474 \\
(2.876)\end{array}$ & $\begin{array}{l}2.126 \\
(1.909)\end{array}$ & $\begin{array}{c}-9.145^{* * *} \\
(1.781)\end{array}$ & $\begin{array}{c}-7.236^{*} \\
(4.110)\end{array}$ & $\begin{array}{c}-11.509^{* * *} \\
(2.974)\end{array}$ \\
\hline Number of observations & 897 & 897 & 963 & 897 & 897 & 959 \\
\hline Number of cantons & 23 & 23 & 26 & 23 & 23 & 26 \\
\hline Wald $\chi^{2}$ & $343628^{* * *}$ & $101519^{* * *}$ & & $953894^{* * *}$ & $171310^{* * *}$ & \\
\hline $\mathrm{F}$ & & & $3.80^{* * *}$ & & & $2.90^{* * *}$ \\
\hline
\end{tabular}

Dependent variable: 3 -year moving average of physician growth in \%; ${ }^{* * *}, * * *$ Coefficient different from zero with an error probability of $10 \%, 5 \%, 1 \%$.

a We apply two GLS-estimation methods: (A) heteroscedastic error structure with cross-sectional correlation, (B) heteroscedastic error structure with cross-sectional correlation and autocorrelation. For the GLS estimations only 23 cantons are included, since for the cantons Jura, Obwalden and Appenzell Innerrhoden data is not available for all the time periods and therefore, the panel is not balanced.

b The within estimator for the fixed-effects model allows the disturbance term to follow an $\mathrm{AR}(1)$ process. The sizes of R-squares are: within $=0.16$, between $=0.16$ and overall $=0.32$ for general practitioners; within $=0.13$, between $=0.11$ and overall $=0.14$ for specialists.

c Time dummies are included in the estimation.

As mentioned earlier, the Swiss government froze the number of private practice sites in 2002. To take into account this measure, we estimate the same model as given by (1) and (2) with additional interaction effects, i.e., we interact all the explanatory variables with the dummy $D_{\text {STOP }}$, which takes the value of one for the years 2002 and later. In addition to the interaction terms, we include the dummy $D_{\text {СтоP }}$ as well as the explanatory variables into the model. The results of the interaction model are reported in Table 5. Looking at interaction terms, we observe that some of the coefficients are significant. Population growth, which negatively affects the growth rate of general practitioners, has an even more negative impact after the physician stop. For the specialists, the opposite holds, but only for one out of three estimation methods. Another determinant, which has a different effect depending on the physician type, is the change of the average age over time. In the simple model, it did not affect the general practitioners. In 
the interaction model, however, the interaction term is positive and significant, meaning that general practitioners mainly grew in areas with larger increases of the average age. For the specialists, the interaction effect is negative, and it weakens the already positive and significant effect of changes of the average age on the growth rate of specialists. We observe a similar pattern for the interaction of $M E D U N I$ with $D_{S T O P}$. For the general practitioners, the coefficient of the interaction variable is positive and highly significant, while it was not statistically different from zero in the simple model. Accordingly, general practitioners became relatively more numerous in cantons with a university hospital. For the specialists, the existence of a university hospital has a dampening effect on their growth rate after introduction of the physician stop. Finally, a higher physician income level also seems to have a positive and significant impact on the growth rate of general practitioners, but no effect on the specialists. Given these results, we conclude that the number of general practitioners mainly grew in areas with higher income levels and with a university hospital. As we have already seen in Figure 1, the average density of general practitioners has decreased after 2002. This stands in line with the negative and highly significant coefficient of the dummy variable $D_{\text {STOP }}$ for the fixed effects estimation. ${ }^{18}$ The specialists, in contrast, do not seem to be affected much by the physician stop. The results of the other variables stand largely in line with those of the simple model, and we do not comment further on them.

18 Note that the variable $D_{\text {STOP }}$ has been dropped in the GLS estimations due to multicollinearity issues. 
Table 5: Physician Growth with Interaction Effects of Physician Stop Dummy DSTOP (1960-2005)

\begin{tabular}{|c|c|c|c|c|c|c|}
\hline \multirow[b]{3}{*}{ Variable $^{c}$} & \multicolumn{3}{|c|}{ General practitioners } & \multicolumn{3}{|c|}{ Specialists } \\
\hline & \multicolumn{2}{|c|}{$\mathrm{GLS}^{\mathrm{a}}$} & \multirow{2}{*}{$\begin{array}{c}\text { Fixed } \\
\text { Effect }^{b} \\
\text { (C) }\end{array}$} & \multicolumn{2}{|c|}{$\mathrm{GLS}^{\mathrm{a}}$} & \multirow{2}{*}{$\begin{array}{c}\text { Fixed } \\
\text { Effect }^{\mathrm{b}} \\
\text { (C) }\end{array}$} \\
\hline & (A) & (B) & & (A) & (B) & \\
\hline L.DENS_GEN & $\begin{array}{c}-0.049^{*} \\
(0.030)\end{array}$ & $\begin{array}{c}-0.076 \\
(0.056)\end{array}$ & $\begin{array}{c}0.001 \\
(0.103)\end{array}$ & $\begin{array}{c}0.000 \\
(0.028)\end{array}$ & $\begin{array}{c}0.000 \\
(0.043)\end{array}$ & $\begin{array}{l}0.402^{\text {*** }} \\
(0.132)\end{array}$ \\
\hline L.DENS_GEN $\times D_{S T O P}$ & $\begin{array}{c}0.086 \\
(0.233)\end{array}$ & $\begin{array}{c}0.058 \\
(0.272)\end{array}$ & $\begin{array}{c}0.827^{*} \\
(0.478)\end{array}$ & $\begin{array}{c}0.454 \\
(0.278)\end{array}$ & $\begin{array}{c}-0.143 \\
(0.304)\end{array}$ & $\begin{array}{r}-0.498 \\
(0.642)\end{array}$ \\
\hline$L . D E N S_{-} G E N^{2}$ & $\begin{array}{c}0.000 \\
(0.000)\end{array}$ & $\begin{array}{c}0.001 \\
(0.000)\end{array}$ & $\begin{array}{r}-0.000 \\
(0.001)\end{array}$ & $\begin{array}{c}0.000 \\
(0.000)\end{array}$ & $\begin{array}{c}0.000 \\
(0.000)\end{array}$ & $\begin{array}{c}-0.003^{* *} \\
(0.001)\end{array}$ \\
\hline L.DENS_GEN $N^{2} \times D_{S T O P}$ & $\begin{array}{r}-0.001 \\
(0.002)\end{array}$ & $\begin{array}{r}-0.001 \\
(0.002)\end{array}$ & $\begin{array}{c}-0.007^{*} \\
(0.004)\end{array}$ & $\begin{array}{c}-0.003 \\
(0.002)\end{array}$ & $\begin{array}{c}0.001 \\
(0.002)\end{array}$ & $\begin{array}{c}0.005 \\
(0.005)\end{array}$ \\
\hline L.DENS_SPE & $\begin{array}{r}-0.008 \\
(0.005)\end{array}$ & $\begin{array}{c}-0.013 \\
(0.009)\end{array}$ & $\begin{array}{c}0.001 \\
(0.031)\end{array}$ & $\begin{array}{c}-0.066^{* * *} \\
(0.004)\end{array}$ & $\begin{array}{c}-0.047^{* * *} \\
(0.012)\end{array}$ & $\begin{array}{r}-0.060 \\
(0.039)\end{array}$ \\
\hline L.DENS_SPE $\times D_{S T O P}$ & $\begin{array}{r}-0.030 \\
(0.027)\end{array}$ & $\begin{array}{c}0.002 \\
(0.032)\end{array}$ & $\begin{array}{c}-0.021 \\
(0.036)\end{array}$ & $\begin{array}{c}0.020 \\
(0.026)\end{array}$ & $\begin{array}{c}0.019 \\
(0.037)\end{array}$ & $\begin{array}{r}-0.007 \\
(0.048)\end{array}$ \\
\hline L.DENS_SPE $E^{2}$ & $\begin{array}{l}0.000^{* *} \\
(0.000)\end{array}$ & $\begin{array}{c}0.000 \\
(0.000)\end{array}$ & $\begin{array}{c}-0.000 \\
(0.000)\end{array}$ & $\begin{array}{l}0.000^{* * *} \\
(0.000)\end{array}$ & $\begin{array}{l}0.000^{* * *} \\
(0.000)\end{array}$ & $\begin{array}{c}0.000 \\
(0.000)\end{array}$ \\
\hline L.DENS_SPE $E^{2} \times D_{S T O P}$ & $\begin{array}{c}0.000 \\
(0.000)\end{array}$ & $\begin{array}{c}0.000 \\
(0.000)\end{array}$ & $\begin{array}{c}-0.000 \\
(0.000)\end{array}$ & $\begin{array}{c}-0.000^{*} \\
(0.000)\end{array}$ & $\begin{array}{r}-0.000 \\
(0.000)\end{array}$ & $\begin{array}{r}-0.000 \\
(0.000)\end{array}$ \\
\hline$\overline{\text { L.GROWTHPOP }}$ & $\begin{array}{c}-0.493^{* * *} \\
(0.050)\end{array}$ & $\begin{array}{c}-0.169^{* * *} \\
(0.064)\end{array}$ & $\begin{array}{c}-0.305^{* * *} \\
(0.104)\end{array}$ & $\begin{array}{l}0.127^{* *} \\
(0.062)\end{array}$ & $\begin{array}{c}0.163 \\
(0.102)\end{array}$ & $\begin{array}{r}-0.049 \\
(0.142)\end{array}$ \\
\hline$\overline{\text { L.GROWTHPOP }} \times D_{S T O P}$ & $\begin{array}{r}-0.976 \\
(0.660)\end{array}$ & $\begin{array}{c}-1.517^{* *} \\
(0.702)\end{array}$ & $\begin{array}{c}1.071 \\
(0.909)\end{array}$ & $\begin{array}{l}1.449^{* *} \\
(0.585)\end{array}$ & $\begin{array}{c}0.507 \\
(0.695)\end{array}$ & $\begin{array}{c}0.295 \\
(1.206)\end{array}$ \\
\hline INCOME & $\begin{array}{c}0.004 \\
(0.008)\end{array}$ & $\begin{array}{c}0.011 \\
(0.013)\end{array}$ & $\begin{array}{c}-0.004 \\
(0.046)\end{array}$ & $\begin{array}{c}0.011 \\
(0.009)\end{array}$ & $\begin{array}{c}0.005 \\
(0.015)\end{array}$ & $\begin{array}{c}0.073 \\
(0.057)\end{array}$ \\
\hline$I N C O M E \times D_{S T O P}$ & $\begin{array}{c}0.0001^{* * *} \\
(0.00002)\end{array}$ & $\begin{array}{c}0.0001^{* * *} \\
(0.00002)\end{array}$ & $\begin{array}{c}0.0001^{*} \\
(0.00004)\end{array}$ & $\begin{array}{l}-0.000^{* * *} \\
(0.000)\end{array}$ & $\begin{array}{c}0.000 \\
(0.000)\end{array}$ & $\begin{array}{c}-0.000 \\
(0.000)\end{array}$ \\
\hline GROWTH INCOME & $\begin{array}{r}-0.015 \\
(0.018)\end{array}$ & $\begin{array}{c}0.000 \\
(0.016)\end{array}$ & $\begin{array}{l}0.103^{* * *} \\
(0.039)\end{array}$ & $\begin{array}{c}-0.038^{* * *} \\
(0.014)\end{array}$ & $\begin{array}{c}-0.054^{* * *} \\
(0.015)\end{array}$ & $\begin{array}{c}-0.088 \\
(0.055)\end{array}$ \\
\hline GROWTH INCOME $\times D_{S T O P}$ & $\begin{array}{c}-0.015 \\
(0.030)\end{array}$ & $\begin{array}{r}-0.037 \\
(0.024)\end{array}$ & $\begin{array}{c}-0.111^{* *} \\
(0.053)\end{array}$ & $\begin{array}{c}0.024 \\
(0.023)\end{array}$ & $\begin{array}{c}0.036 \\
(0.023)\end{array}$ & $\begin{array}{c}0.064 \\
(0.076)\end{array}$ \\
\hline$A G E$ & $\begin{array}{r}-0.025 \\
(0.042)\end{array}$ & $\begin{array}{c}0.010 \\
(0.084)\end{array}$ & - & $\begin{array}{l}0.337^{* * *} \\
(0.046)\end{array}$ & $\begin{array}{l}0.321^{* * *} \\
(0.110)\end{array}$ & - \\
\hline$A G E \times D_{S T O P}$ & $\begin{array}{c}0.029 \\
(0.230)\end{array}$ & $\begin{array}{c}-0.331 \\
(0.281)\end{array}$ & - & $\begin{array}{c}-0.091 \\
(0.284)\end{array}$ & $\begin{array}{r}-0.246 \\
(0.336)\end{array}$ & - \\
\hline GROWTH AGE & $\begin{array}{r}-0.016 \\
(0.015)\end{array}$ & $\begin{array}{r}-0.014 \\
(0.033)\end{array}$ & - & $\begin{array}{l}0.136^{* * *} \\
(0.014)\end{array}$ & $\begin{array}{l}0.111^{* * *} \\
(0.041)\end{array}$ & - \\
\hline
\end{tabular}




\begin{tabular}{|c|c|c|c|c|c|c|}
\hline \multirow[b]{3}{*}{ Variable $^{c}$} & \multicolumn{3}{|c|}{ General practitioners } & \multicolumn{3}{|c|}{ Specialists } \\
\hline & \multicolumn{2}{|c|}{$\mathrm{GLS}^{\mathrm{a}}$} & \multirow{2}{*}{$\begin{array}{c}\text { Fixed } \\
\text { Effect }^{b} \\
\text { (C) }\end{array}$} & \multicolumn{2}{|c|}{$\mathrm{GLS}^{\mathrm{a}}$} & \multirow{2}{*}{$\begin{array}{c}\text { Fixed } \\
\text { Effect }^{b} \\
\text { (C) }\end{array}$} \\
\hline & (A) & (B) & & (A) & (B) & \\
\hline GROWTH AGE $\times D_{S T O P}$ & $\begin{array}{l}0.246^{* * *} \\
(0.053)\end{array}$ & $\begin{array}{l}0.303^{* * *} \\
(0.081)\end{array}$ & - & $\begin{array}{c}-0.173^{* * *} \\
(0.048)\end{array}$ & $\begin{array}{r}-0.172^{*} \\
(0.088)\end{array}$ & - \\
\hline HOSPITAL BEDS & $\begin{array}{c}0.027 \\
(0.035)\end{array}$ & $\begin{array}{c}-0.035 \\
(0.070)\end{array}$ & - & $\begin{array}{c}0.050 \\
(0.041)\end{array}$ & $\begin{array}{c}0.098 \\
(0.106)\end{array}$ & - \\
\hline HOSPITAL BEDS $\times D_{S T O P}$ & $\begin{array}{c}-0.125 \\
(0.119)\end{array}$ & $\begin{array}{c}-0.143 \\
(0.164)\end{array}$ & - & $\begin{array}{l}0.568^{* * *} \\
(0.168)\end{array}$ & $\begin{array}{c}0.457^{*} \\
(0.268)\end{array}$ & - \\
\hline GROWTH HOSPITALBEDS & $\begin{array}{c}-0.013^{* *} \\
(0.006)\end{array}$ & $\begin{array}{r}-0.018 \\
(0.013)\end{array}$ & - & $\begin{array}{l}0.035^{* * *} \\
(0.006)\end{array}$ & $\begin{array}{l}0.032^{* *} \\
(0.013)\end{array}$ & - \\
\hline GROWTH HOS.BEDS $x D_{\text {STOP }}$ & $\begin{array}{c}-0.032 \\
(0.024)\end{array}$ & $\begin{array}{c}-0.043 \\
(0.034)\end{array}$ & - & $\begin{array}{c}0.021 \\
(0.022)\end{array}$ & $\begin{array}{r}-0.032 \\
(0.031)\end{array}$ & - \\
\hline MEDUNI & $\begin{array}{c}-0.114 \\
(0.103)\end{array}$ & $\begin{array}{c}0.089 \\
(0.212)\end{array}$ & - & $\begin{array}{l}1.230^{* * *} \\
(0.108)\end{array}$ & $\begin{array}{l}0.812^{* * *} \\
(0.302)\end{array}$ & - \\
\hline$M E D U N I \times D_{S T O P}$ & $\begin{array}{l}2.400^{* * * *} \\
(0.463)\end{array}$ & $\begin{array}{l}1.627^{* * *} \\
(0.603)\end{array}$ & - & $\begin{array}{l}-2.330^{* * *} \\
(0.434)\end{array}$ & $\begin{array}{c}-1.309 \\
(0.820)\end{array}$ & - \\
\hline INCOME PHYSICIANS & $\begin{array}{c}-0.006 \\
(0.004)\end{array}$ & $\begin{array}{c}-0.007 \\
(0.009)\end{array}$ & - & $\begin{array}{c}-0.009^{* *} \\
(0.004)\end{array}$ & $\begin{array}{c}0.001 \\
(0.009)\end{array}$ & - \\
\hline$I N C P H Y S I C I A N S \times D_{\text {STOP }}$ & $\begin{array}{l}0.071^{* * *} \\
(0.014)\end{array}$ & $\begin{array}{l}0.057^{* *} \\
(0.023)\end{array}$ & - & $\begin{array}{c}0.020 \\
(0.014)\end{array}$ & $\begin{array}{c}0.013 \\
(0.021)\end{array}$ & - \\
\hline$D_{S T O P}$ & - & - & $\begin{array}{l}-35.210^{* *} \\
(15.918)\end{array}$ & - & - & $\begin{array}{c}18.586 \\
(21.331)\end{array}$ \\
\hline Constant & $\begin{array}{c}-20.802^{* *} \\
(9.881)\end{array}$ & $\begin{array}{l}-8.325 \\
(12.400)\end{array}$ & $\begin{array}{c}-1.294 \\
(1.206)\end{array}$ & $\begin{array}{l}-15.315 \\
(12.352)\end{array}$ & $\begin{array}{c}8.217 \\
(14.923)\end{array}$ & $\begin{array}{l}-5.410^{* * *} \\
(1.913)\end{array}$ \\
\hline Number of observations & 966 & 966 & 1041 & 966 & 966 & 1037 \\
\hline Number of cantons & 23 & 23 & 26 & 23 & 23 & 26 \\
\hline Wald $\chi^{2}$ & $557379^{* * *}$ & 3017 & $439^{* * *}$ & $1290293^{* * *}$ & $251110^{* * *}$ & \\
\hline $\mathrm{F}$ & & & $11.379^{* * *}$ & & & $3.89^{* * *}$ \\
\hline
\end{tabular}

Dependent variable: 3 -year moving average of physician growth in $\%$; ${ }^{(*)},{ }^{* * *}$ Coefficient different from zero with an error probability of $10 \%, 5 \%, 1 \%$.

a We apply two GLS-estimation methods: (A) heteroscedastic error structure with cross-sectional correlation, (B) heteroscedastic error structure with cross-sectional correlation and autocorrelation. For the GLS estimations only 23 cantons are included, since for the cantons Jura, Obwalden and Appenzell Innerrhoden data is not available for all the time periods and therefore, the panel is not balanced.

b The within estimator for the fixed-effects model allows the disturbance term to follow an $\mathrm{AR}(1)$ process. The sizes of R-squares are: within $=0.39$, between $=0.04$ and overall $=0.46$ for general practitioners; within $=0.18$, between $=0.13$ and overall $=0.16$ for specialists.

c Time dummies are included in the estimation. 


\section{Conclusions}

The focus of this paper is on the evolution of physician densities in the Swiss cantons over the last 45 years. We used a physician location model relating physician growth in a canton to (i) the existing number of physicians in an area, (ii) commonly used determinants of the demand for physician services such as population growth, per capita income and age, and (iii) factors that determine the medical infrastructure of an area, i.e. the number of hospital beds and the existence of a university hospital. We investigated these effects separately for general practitioners and specialists. Finally, we also studied potential impacts of the physician stop, which was introduced by the Swiss government in 2002 .

From our analysis, we find that physicians choose locations based on factors included in our model. Specialists are attracted to areas that offer a good professional climate, higher population growth and an older population. Also, specialists seem to avoid areas where physician density of specialists has reached a certain level. In addition, our results show that specialists are able to substitute services provided by general practitioners. Being unique providers of certain services, specialists settle first in larger cities and force general practitioners to locate in regions characterized by lower population growth. Finally, we show that the physician stop mainly affected general practitioners, whose density level decreased on average after 2002.

Notwithstanding the rather extensive literature on physician behavior, more research is needed, and this holds true particularly for Switzerland. For instance, physician supply is often considered together with market failure, and numerous studies focus on how greatly services are induced by physicians. As LABELLE et al. (1994) point out, however, the important question is about the consequences of demand inducement for consumers' utility, i.e., what are the effects of induced services on the health status of the patients. As mentioned earlier, our data did not allow us to study these issues. Furthermore, the regional density of physicians in independent practice sites is also significantly associated with consultation rates. Accordingly, this additional information should be taken into account (Busato and Kuenzi, 2008). Also, there is political pressure to the effect that health insurance companies may no longer be forced to sign contracts with every physician of their canton, thus introducing more competitive elements into the Swiss health care market. On the other hand, the introduction of aptitude tests for medical studies at most Swiss universities as well the establishment of entry barriers for new medical practices - both measures that have been put in place recently - may reduce pressure from the supply side. All these circumstances will 
certainly further affect the distribution of physicians, and some of these issues will be addressed in future research.

\section{Appendix}

Table 6: Physician Densities for the Swiss Cantons in 2005

\begin{tabular}{|c|c|c|c|c|c|}
\hline \multicolumn{2}{|c|}{ Canton } & \multicolumn{2}{|c|}{ Generalists } & \multicolumn{2}{|c|}{ Specialists } \\
\hline & & $\begin{array}{c}\text { Per } 100,000 \\
\text { persons }\end{array}$ & Rank & $\begin{array}{c}\text { Per } 100,000 \\
\text { persons }\end{array}$ & Rank \\
\hline AG & Aargau & 39 & 22 & 112 & 16 \\
\hline AR & Appenzell Ausserrhoden & 40 & 21 & 80 & 25 \\
\hline AI & Appenzell Innerrhoden & 52 & 9 & 120 & 13 \\
\hline BL & Basel-Land & 52 & 6 & 160 & 7 \\
\hline BS & Basel-Stadt & 50 & 11 & 147 & 8 \\
\hline $\mathrm{BE}$ & Bern & 48 & 13 & 327 & 1 \\
\hline FR & Fribourg & 38 & 23 & 115 & 14 \\
\hline GE & Genf & 33 & 26 & 297 & 2 \\
\hline GL & Glarus & 58 & 3 & 94 & 20 \\
\hline GR & Graubünden & 53 & 5 & 123 & 12 \\
\hline JU & Jura & 52 & 8 & 112 & 17 \\
\hline LU & Luzern & 47 & 14 & 104 & 19 \\
\hline NE & Neuenburg & 41 & 19 & 170 & 5 \\
\hline NW & Nidwalden & 36 & 24 & 82 & 24 \\
\hline OW & Obwalden & 63 & 1 & 54 & 26 \\
\hline SH & Schaffhausen & 46 & 15 & 114 & 15 \\
\hline SZ & Schwyz & 62 & 2 & 135 & 9 \\
\hline $\mathrm{SO}$ & Solothurn & 51 & 10 & 112 & 18 \\
\hline SG & St. Gallen & 45 & 16 & 86 & 21 \\
\hline $\mathrm{TE}$ & Tessin & 48 & 12 & 84 & 22 \\
\hline TG & Thurgau & 35 & 25 & 167 & 6 \\
\hline UR & Uri & 40 & 20 & 84 & 23 \\
\hline VD & Waadt & 41 & 18 & 203 & 3 \\
\hline VS & Wallis & 43 & 17 & 133 & 10 \\
\hline ZG & Zug & 52 & 7 & 132 & 11 \\
\hline $\mathrm{ZH}$ & Zürich & 53 & 4 & 177 & 4 \\
\hline
\end{tabular}




\section{References}

Bhargava, A., L. Franzini and W. Narendranathan (1982), "Serial Correlation and the Fixed Effects Model”, Review of Economic Studies, 49 (4), pp. 533-549.

Bolduc, D., B. Fortin and M. A. Fournier (1996), "The Effect of Incentive Policies on the Practice Location of Doctors: A Multinomial Probit Analysis", Journal of Labor Economics, 14, pp. 703-732.

Busato A. and B. Kuenzi (2008), "Primary Care Physician Supply and Other Key Determinants of Health Care Utilization: The Case of Switzerland", BMC Health Services Research, 2008, 8:8.

Chomitz, K. M., G. Setiadi, A. Azwar, I. Nusye and R. Widiyarti (1998), What Do Doctors Want? Developing Incentives for Doctors to Serve in Indonesia's Rural Areas, World Bank, Development Research Group.

Cooper, R. A., T. E. Getzen, H. J. McKee and P. Laud (2002), "Economic and Demographic Trends Signal an Impeding Physician Shortage", Health Affairs, 21, pp. 140-154.

Dartmouth Medical School (2007), The Dartmouth Atlas of Health Care in the United States. Chicago: American Hospital Publishing.

De Jaegher, K. and M. Jegers (2000), "A Model of Physician Behaviour with Demand Inducement”, Journal of Health Economics, 19, pp. 231-258.

Domenighetti, G. and L. Crivelli (2001), "Sécurité de l'approvisionnement en médecine de ville dans le cadre de la suppression de l'obligation de contracter», Working paper MecoP and iems.

Fisher E. S. and J. E. Wennberg (2003), "Health Care Quality, Geographic Variations, and the Challenge of Supply-Sensitive Care", Perspectives in Biology and Medicine, 46, pp. 69-78.

Folland, S., A. C. Goodman and M. Stano (2001), The Economics of Health and Health Care, 3rd. ed., Upper Saddle River: Prentice-Hall.

Foster, S. A. and W. L. Gorr (1992), "Federal Health Care Policy and the Geographic Diffusion of Physicians: A Macro-Scale Analysis”, Policy Sciences, 25, pp. 117-134.

Gilliand, P. and P. Eichenberger (1981), „Demographie der künftigen Ärzteschaft in der Schweiz: Perspektiven und ihre Auswirkungen auf lange Sicht" (Demography of Future Physicians: Perspectives and Effects in the Longterm), Schweizerische Ärztezeitung, 62 (38), pp. 2759-2770.

Hasler N. and M. Reichert (2008), „Einkommensentwicklung der freien Ärzteschaft der Schweiz in den Jahren 2004 (neu) und 2003 (Re-Evaluation)“, Schweizerische Ärztezeitung, 89:6. 
Hurley, J. (1990), "Simulated Effects of Incomes-Based Policies on the Distribution of Physicians”, Medical Care, 28, pp. 221-238.

Koenig L., J. M. Siegel, A. Donson, K. Hearle, S. Ho and R. RudowITz (2003), "Drivers of Healthcare Expenditures Associated with Physician Services", The American Journal of Managed Care, 9 (Special Issue 1), pp. SP34-42.

Kristiansen, I. S. and O. H. Førde (1992), "Medical Specialists' Choice of Location: The Role of Geographical Attachement in Norway", Social Science and Medicine, 34, pp. 57-62.

Labelle, R., G. Stoddart and T. Rice (1994), "A Re-Examination of the Meaning and Importance of Supplier-Induced Demand", Journal of Health Economics, 13, pp. 347-368.

Newhouse, J. P., A. P. Williams, B. W. Bennett and W. B. Schwartz (1982), "Does the Geographical Distribution of Physicians Reflect Market Failure?", Bell Journal of Economics, 13 (2), pp. 493-505.

Schellhorn, M. (2001), "The Effect of Variable Health Insurance Deductibles on the Demand for Physician Visits", Health Economics, 10, pp.441-456.

Schmid, H. (1984), „Der Einfluss zunehmender Ärztedichte auf die Kosten der Krankenversicherung" (Influence of an Increasing Physician Density on the Cost of Health Insurance), Schweizerische Ärztezeitung, 65 (11), pp. 497-506.

Timmermans, H. and R. G. Golledge (1990), "Applications of Behavioural Research on Spatial Problem II: Preference and Choice", Progress in Human Geography, 14, pp.311-354.

U.S. Department of Health and Human Services (2006), Physician Supply and Demand: Projections to 2020.

Wagstaff, A. (1986), “The Demand for Health. Some New Empirical Evidence”, Journal of Health Economics, 5, pp. 195-233. 


\section{SUMMARY}

Our paper investigates the geographical distribution of physicians across the Swiss cantons over the years 1960 to 2005 . We use a physician location model relating physician growth in a canton related to (i) the existing number of physicians in an area, (ii) commonly used determinants of the demand for physician services such as population growth, per capita income and age, and (iii) factors that determine the medical infrastructure of an area, i.e. the number of hospital beds and the existence of a university hospital. We analyze the effects separately for general practitioners and specialists and find that the two physician types react differently to certain factors included in our analysis. 